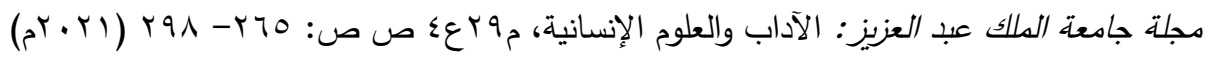

\title{
مقاربة سِيميولوجية للتحليل الرَّسمبياني في الأطالس الجغرافية. تطبيق تقنية المصفوفة التراتبية على مدينة جدة
}

\author{
أ.د. محسن الهادي ذياب \\ mdhieb@kau.edu.sa أستاذ دكتور (باحث رئيس) \\ د. عبد الحميد محمد جميل: أستاذ مساعد \\ د. محمد عوض العمري: أستاذ مشارك \\ قسم الجغرافيا ونظم المعلومات الجغرافية - كلية الآداب والعلوم الإنسانية \\ جامعة الملك عبد العزيز
}

مستخلص. كان للثورة الرقمية الحديثة الأثر العميق في العمل الخرائطي والرسمبياني '، تصميما وإنتاجا، وبخاصة في

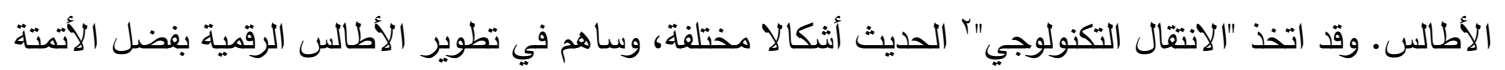

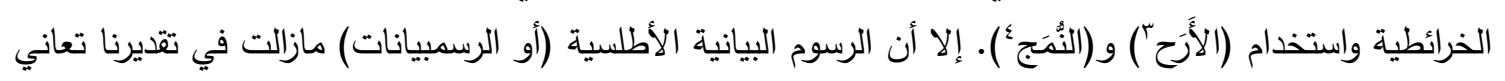
من نقص فادح في الجانب "الَعلاميْ-السِيميولوجي"، حيث تشوبها هنات متعددة تتعلق غالب الأمر بالاختيار العشوائي للنمط الرسمبياني، والإسهاب في استخدام بعض الأصناف من الرسوم دون غيرها، كالأعمدة المتراكبة

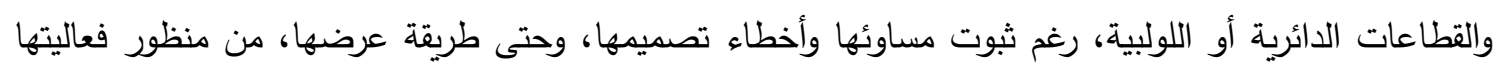
ومدى تأديتها وظيفتها الأولى كوسيلة تبليخ رسالة، ولا كوسيلة تجميل وزخرفة أو زركثة.

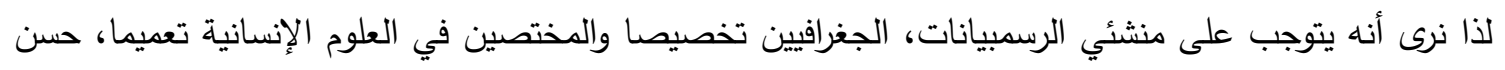
اختيار الأشكال الرسمبيانية، وحسن تصميمها، من منظور علامي -سيميولوجي، لتيسير عملية قراءتها واستيعابها،

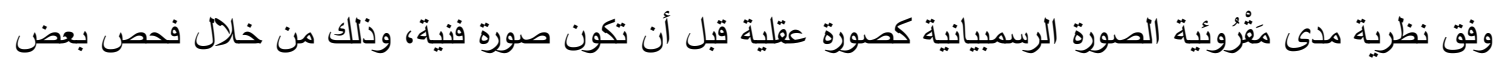
النماذج المتكررة واقتراح أخرى بديلة أكثر نجاعة. ذلك أن معظم المنتجات الرسمبيانية تولي اهتماما متزايدا لمسائل

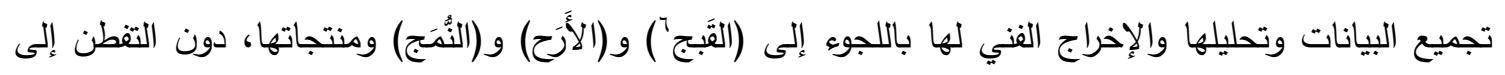
مسائل استيعابها واستخدامها السليم والاستفادة منها من قبل أوسع شريحة من المستخدمين.

' استخدمنا عبارتي رسمبيان اختصار ال "رسم بياني" ورسمبياني كصفة تدل أن الثكل ينتمي إلى فصيلة الرسوم البيانية.

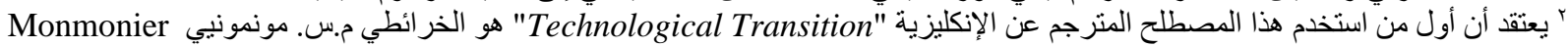

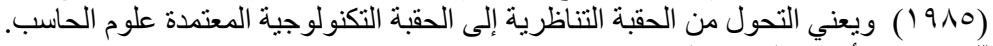
كَ اختصار لأنظمة الرسوم الحاسوبية.

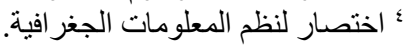

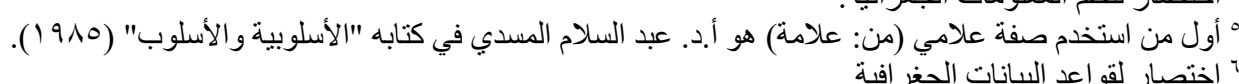


بعد تقديم الخلفية النظرية للتصميم الرسمبياني كحقل معرفي ذي علاقة بنظريتي الصورة والاتصال، يكمن الهدف الرئيس من البحث في التتويه بضرورة توخي الحذر والموضوعية في اختيار الرسمبيانات المناسبة ضمن الأطالس،

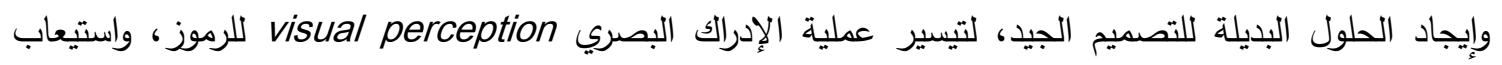
الإرساليات messages من خلال عرض القواعد والأسس التي تقوم عليها، واستعراض أهم الأخطاء في إنشاء وتصميم الرسمبيانات. وقد حاولنا تطبيق ذلك من خلال قراءة للرسوم البيانية بأطلس المملكة وتطبيق ذلك على ألى أمثلة عن مدينة جدة للاستدلال بها ضمن أطلس جدة الرقمي. الكلمات المفتاحية: الرسوم البيانية - المقاربة العلامية - السيميولوجية - أطلس جدة - أخطاء الرسوم الثائعة.

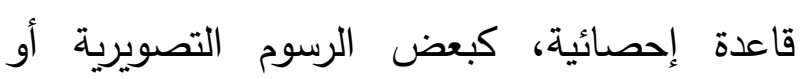
الإيحائية. ولعل الثورة الرقمية، والحوسبة، والرقمنة، وبروز البرمجيات المتخصصة وغير المتخصصة في إنشاء الرسمبيانات، مثل إيكسل Excel و وSPSS، والبرمجيات المفتوحة، والبعض من برمجيات (الأَرح)

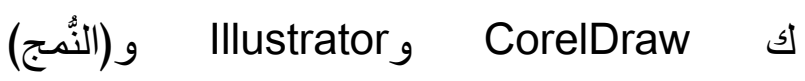
ك Maplnfo و MrcGIS، كل هذه العوامل أسههت في الانتشار الواسع لهذا الضرب من التعبير البياني. كما إن استخدام الرسوم صار يشمل شريحة متزايدة من المجالات والحقول المعرفية، وفق أشكال ونماذج متنوعة ومبتكرة. وأصبح تصميمها وتتفيذها ينطبقان على أوعية اتصالية مستجدة، منها ما هو ساكن ومنها

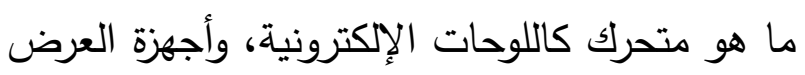
الرأسي الضوئي، والمطويات، والشرائح، بالإضافة إلى مائ الأوعية التقليدية كاللوحات القلابة، والمنشورات الجغرافية، والمجلات والنشريات الإحصائية، والموسوعات، ومختلف المنشورات الورقية ومنها بصفة خاصة الأطالس.

\section{المقدمة}

إلى جانب الخرائط، تُشَكل الرسوم البيانية (أو ما أطلقنا عليه الرسمبيانات) طريقةً ثانية لتمثيل البيانات الجغرافية وغير الجغرافية. وبشكل عام، تُستخدم هذه الرسوم لتمثيل البيانات الإحصائية وغير الإحصائية وفق نظام إحداثي غير جغرافي، حيث لا يمثل الفضاءُ الجغرافي العُنصرَ الرئيسي للبحث. الجدير بالذكر أنه توجد مصطلحات وتسميات كثرة ومتتوعة للرسمبيانات في البلدان العربية، نذكر منها المخططات والرسومات والخطاطات والمبيانات والإبانات والمقاطع والقطاعات والمنحنيات والمدرجات والكروكيات وغيرها، تعبيرا عن أشكال الرسمبيانات الخطية والنقطية والمساحية والحجمية أو المركبة. كما توجد نماذج معروفة للرسوم البيانية في الأدبيات الجغرافية كالأهرامات السكانية، والرسوم البيحرارية (أو المطرية الحرارية)، والمنحنيات الإخصائية كمنحنى لورنز Lorenz أو منحنى غوس Gauss أو منحنى

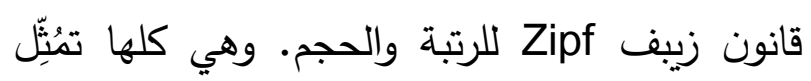
البياناتِ الإحصائية المنفصلة أو المتصلة؛ الكمية أو

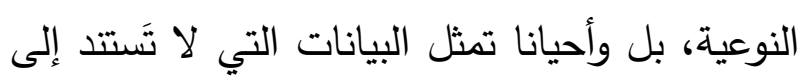


ذو الصبغة النظرية، إلى اقتراح جملة من الضوابط والاشتراطات لتطبيقها في أطلس جدة الرقمي المزمع

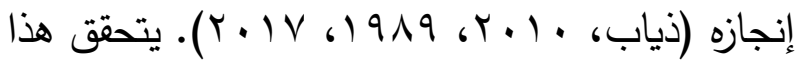
الهدف العام باستخدام آلية الخطاطات القاعدية basic schemes للرسوم البيانية القائعة على نظرية الصور image theory يهدف هذا البحث أساسا إلى تقييم بعض الرسوم البيانية المستخدمة بإسهاب في البحوث الجغرافية وما تودي به الاختيارات العشوائية إلى التقليص من لبن فعاليتها وأدائها مهمتها الاتصالية. ثم من خلاتل

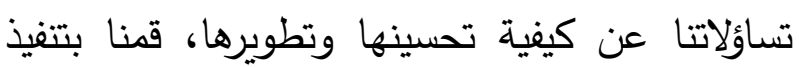

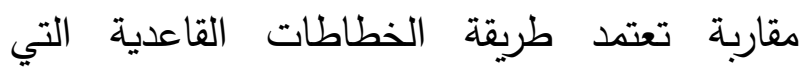
استتبطها بيرتين وأثبتت فعاليتها في البيانات المتعددة

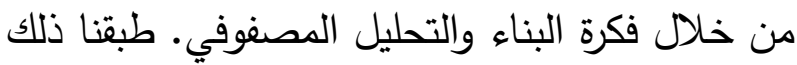
على أحياء مدينة جدة من خلال مجموعة واسعة من البيانات كان الهدف منها التوصل إلى خريطة تأليفية ترصد التباينات المكانية كان طَرْحُا هنا هو أن تجنب الاستخدام العشوائي

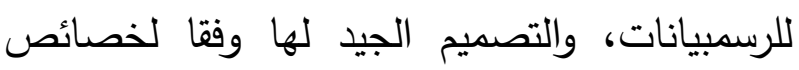
البيانات من اتساق وتجانس وملاءمة، وعدم الانسياق على ما توفره البرمجيات الحاسوبية من تطبيقات يقلل من الكلفة الذهنية mental cost لزبف (Zipf) 9 9 19 ) ويودي إلى منتجات خرائطية تضمن تبليغ المعلومات بالكفاءة اللازمة. نقول هذا اليوم بالرغم من توفر شريحة واسعة-متوسعة من الرسمبيانات التي بلي
بقيت مسألة تقييم مردوديتها وفعاليتها قائمة، وذلك من خلال مدى تحقيق أهدافها في إيصال المعلومة

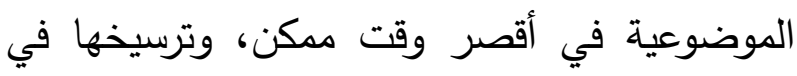
ذاكرة المستخدم، ومن خلال تمثيلها البيانات بطريقة ومنية مقبولة ومستوعبة، والفائدة الحاصلة فعلا في البحوث. ولم يحضَ استخدامُ الرسوم البيانية في الحالات

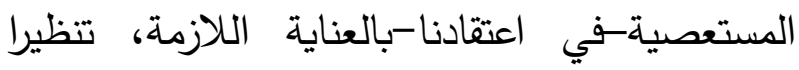
وتكريسا ـ وهذه الملحوظة جائزة بالرغم من وجود بعض لئل البحوث والخلفيات والمرجعيات النظرية على غرار ما قام به أخصائيون ك (توفتي Tufte، 1997,1990،

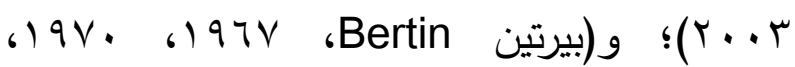

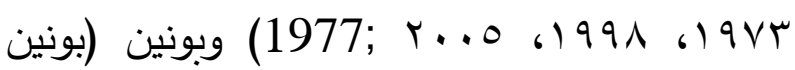
Bord Bonin et Blin المعلومة للمستخدم كأدوات مساعدة على القراءة البصرية، تقطع رتابة النصوص والخطابات. منهجية البحث، أهدافه وفرضياته بداية وقع استعراض أهم المحطات التاريخية للرسوم البيانية من ماكروب Macrobe إلى بيرتين Bertin تم فيها التركيز على النماذج الحديثة وتطورها الحديث. ثم استعرضنا أمثلة لبعض المنتجات الجغرافية المستخدمة للرسمبيانات، مستتبطة من أطلس المملكة، ربينا وقمنا بقراءة نقدية متمعنة في كيفية تحسينها، وذلك بوضع جملة من الأسس النظرية تعتمد مقاربة علامية سيميولوجية مستلهمة من الخطاطات القاعدية لبيرتين. ثم قمنا بتطبيق هذه القواعد يهدف هذا البحث 
رسمبيان يحمل بيانات كمية يحاكي إلى حد ما الرسوم

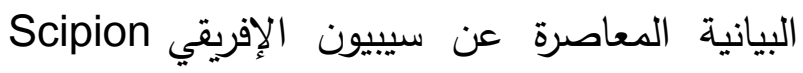
l'Africain الحضارة الرومانية (الثكل () بينما قد نجد آثارا

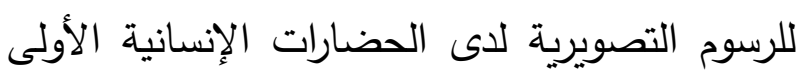
مرسومة في الكهوف أو على بعض الأوعية كالصلصال والطين قبل منذ آلاف السنين.
توفرها البرمجيات الحاسوبية وتتامي ضروبها وأعدادها

$$
\text { ومجالات استخدامها. }
$$

من الصعب جدَّا إجراء جردِ شامل لجميع الأدبيات والوثائق والأيقونات ذات الصلة بالرسوم البيانية. لكن جن الكرداه يبدو أنها ظهرت منذ حقب بعيدة، حيث نجد أثرا لأول

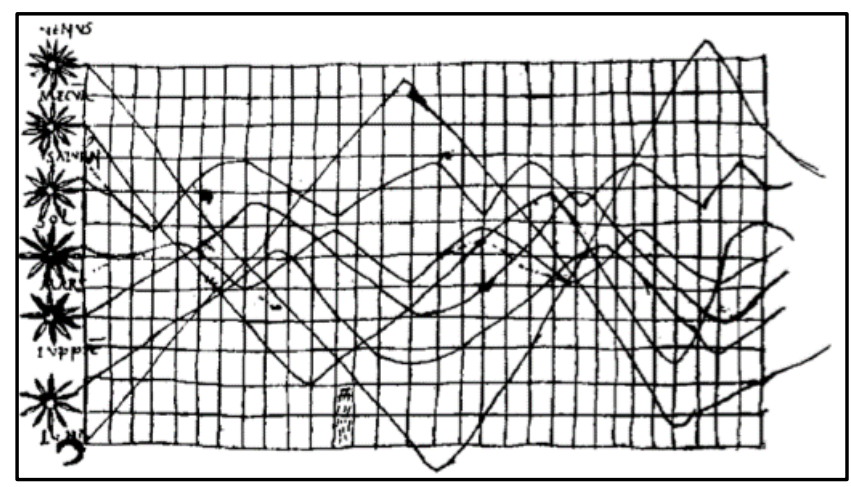

(الثكل 1): نموذج لرسم بياني عن حركة الكواكب تعليقا عن "حلم القائد الروماني" "Commentaire au songe du roi Scipion"

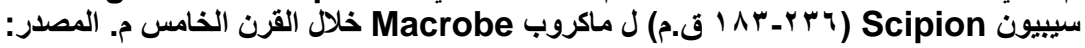

https://fr.wikipedia.org/wiki/Commentaire au Songe de Scipion

وظهر في القرن Vام. الفلكي الألماني اليسوعي شينر Scheiner مخترع جهاز "البانتوغراف" أو المنساخ الذي

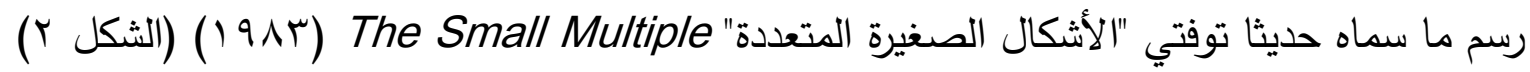
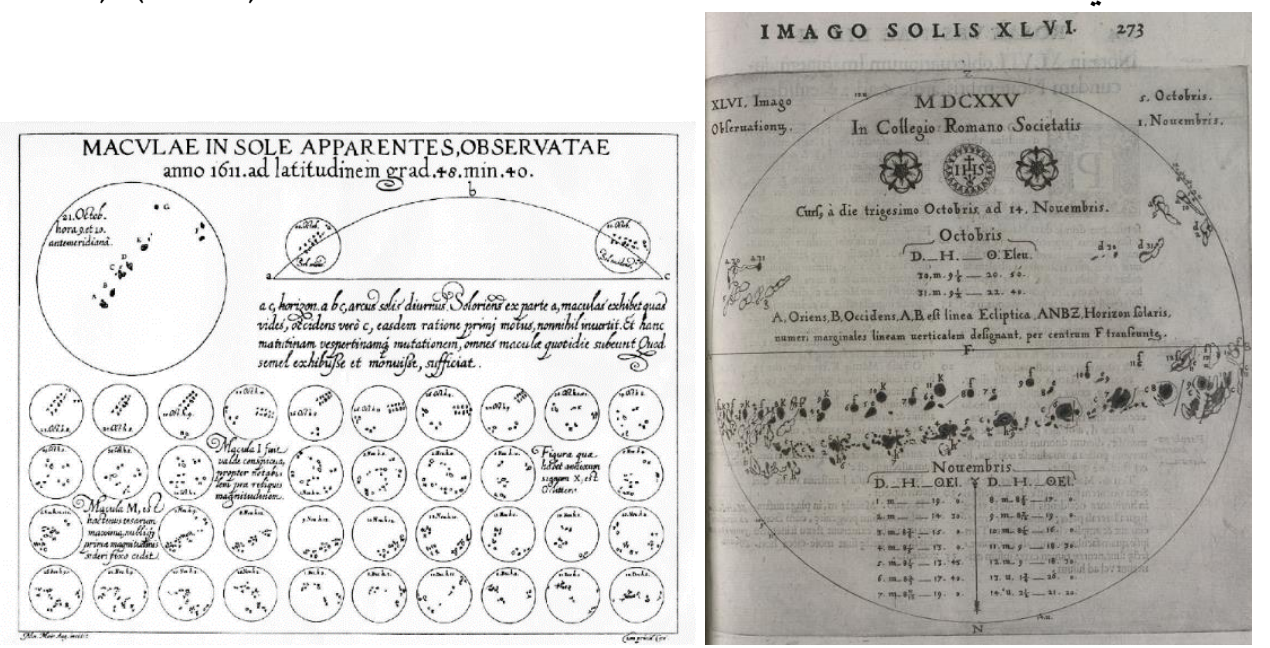

Scheiner C. (1620). Oculus, hoc est: الشكل (ץ) : ييين الرسمان البقع الشمسية المتغيرة عبر الزمن. المصدر: Fundamentum opticum, Innsbruck \Gallica. 
الإحصائية، عدة ضروب وأشكال في نهاية القرن الثامن عشر وبداية القرون التاسع عشر ، كتلك المبنية

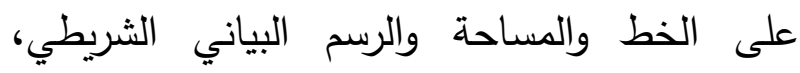

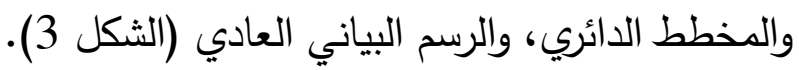

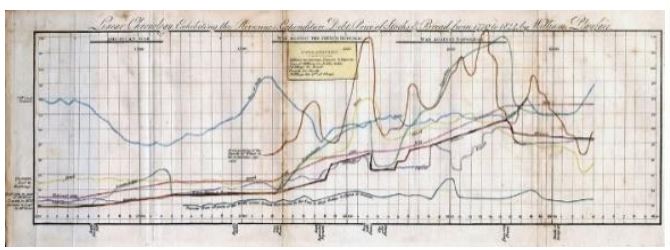

ويجب انتظار عصر النهضة في أوروبا كي نجد استخداما متواترا للرسمبيانات الحديثة بصفة مكثئة،

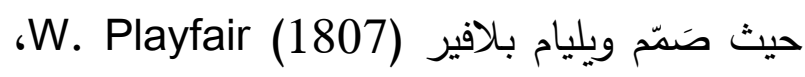
وهو من رواد الأساليب الرسومية الحديثة للبيانات
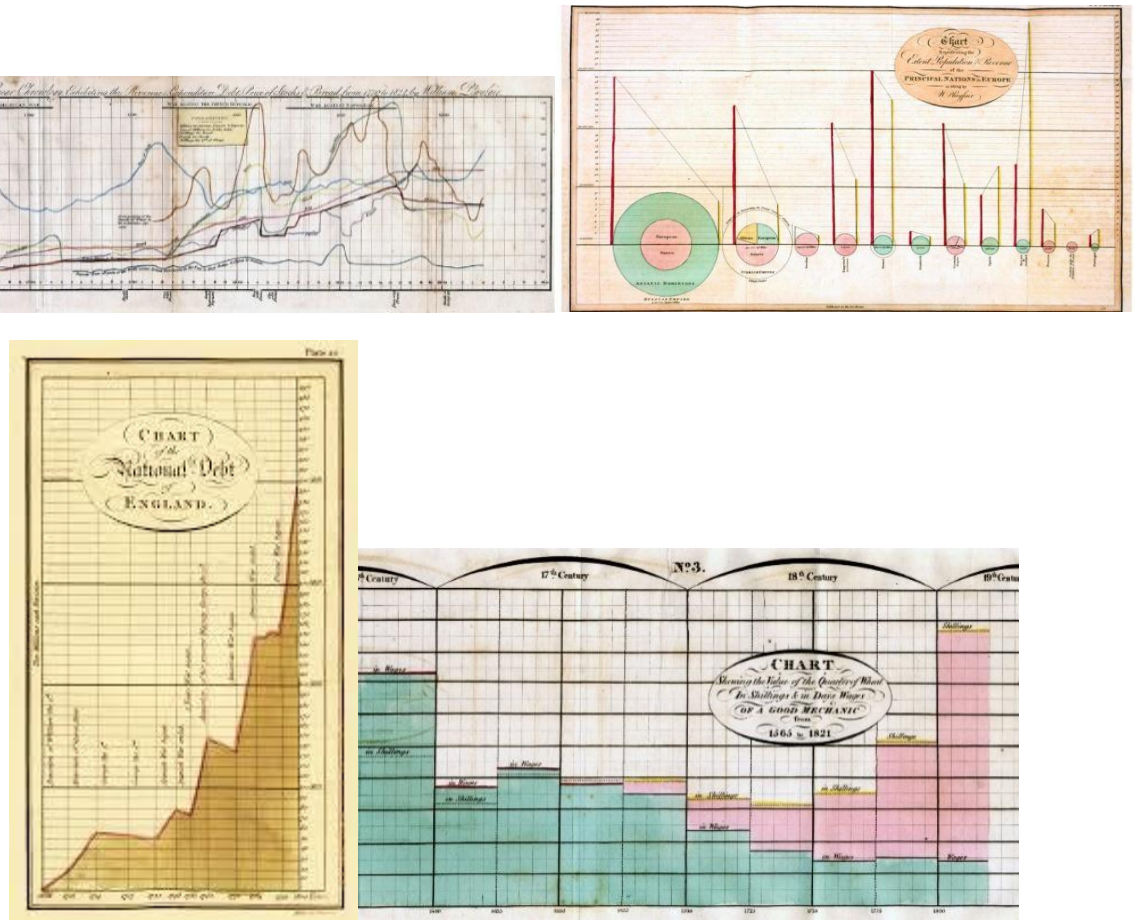

https://fr.wikipedia.org/wiki/William Playfairالثكل ؛ : نماذج من رسوم ويليام بلايفير. المصدر: موقع ويكيبيديا

كما أنشأ جوزيف مينارد J. Minard الفرنسي، بالتزامن، جملة من الرسوم البيانية يمتاز البعض منها بكونه رُسِم على الخرائط، نذكر منها رسمه الثهير الذي يبرز تجسيدًا لحملة نابليون بونابارت في روسيا (الثكل ه).

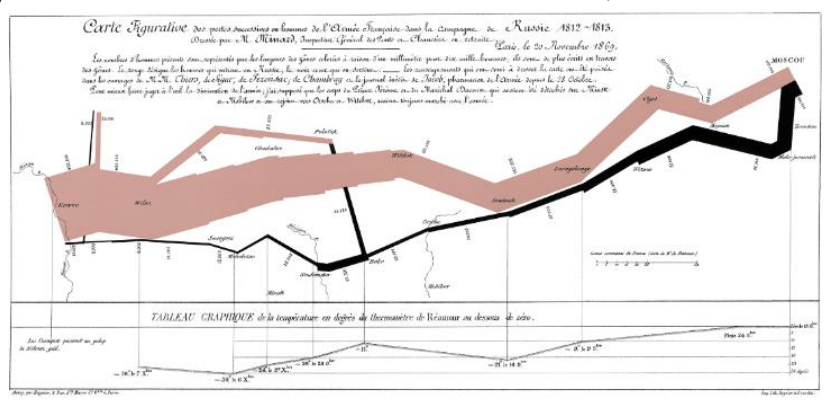

الثكل ه: نموذج رسم جوزيف مينارد عن حملة نابليون في روسيا، يبين باللون البني تناقص أعداد الجنود ذهابا من فرنسا حتى موسكو، ثم إيابا وباللون الأسود من موسكو حتى فرنسا. https://fr.wikipedia.org/wiki/Charles Joseph Minard: المصدرد 
ا ـ منهجية البحث: الجهاز الأدواتي وعمل بيرتين إلى جانب المراجع الحديثة الأخرى التي تتاولت مسألة التئ الرسمبيانات في الجغرافيا، يمكن اعتبار مُؤَلَّفَ بيرتين

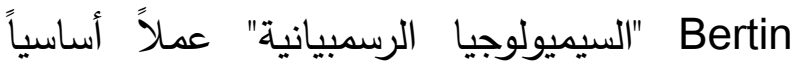
مُؤسيّساً لنظرية التعبير البياني بالرسوم البيانية

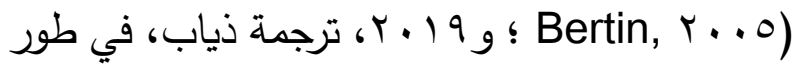
الطباعة). فعلى الرغم من اعتبار "المتغيرات البصرية"

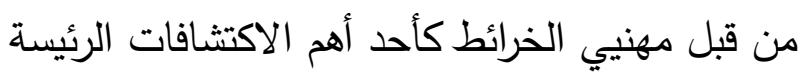
للكتاب، فقد ابتكر بيرتين مجموعة من التقنيات

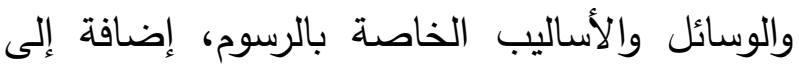
تقنين مبادئ وأسس النظام الرسمبياني Graphical .system

فهو يَعتبر الرسمبيانات أحد الأصناف الثلاثة لكل الرسوم الموجودة في عنوان مؤلفه إلى جانب الخرائط والشبكات الرسمبيانية، والتي تعتبر هي أيضا حالاتِ متميزة من الرسوم البيانية. ويوفر هذا المؤلَّف أيضا

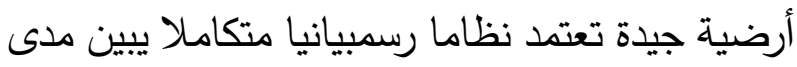

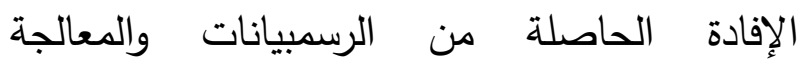

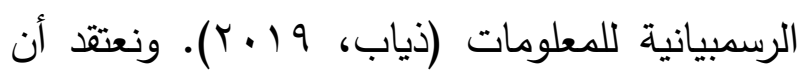
هذه المقاربة العلامية-السيميولوجية مفيدة في استخدامها في الأطالس في بحثنا هذا، بعد التقييم

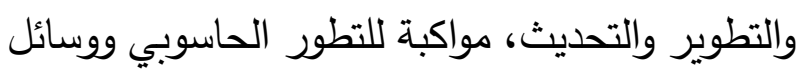
الاتصال الحديثة ونحاول تطبيقها على أطلس مدينة
ويمكن اعتبار المهندس الأمريكي و. سي. برينتون W.C. Brinton كتابه "الوسائل البيانية -تقديم الحقائق" (9 919 (1)، إذ هن يعد من أشهر ما كُتب عن الرسوم البيانية في بداية القرن العشرين بخلفية نظرية. E. أما في العصر الحديث، فقد ألف إدوارد توفتي (199 • 19194) Tufte من الكتب المرجعية ضمنها بعض مبادئ وظائف

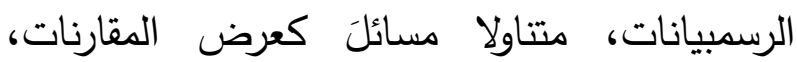
وإظهار السببية، وعرض البيانات متعددة المتغيرات،

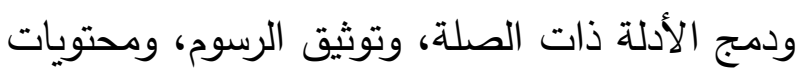
العد أكثر من أي شيء، بصيغة نقدية. كما اهتم

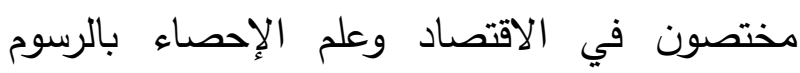
البيانية لاستخدامهم إياها للاستدلال في بحوثهم ومنشوراتهم. وفي اعتقادنا، لا نجد جهازا أدواتيا متكاملا ووفق مقاربة علامية - سيميولوجية حول الرسوم البيانية

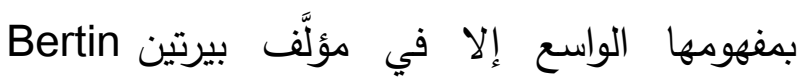

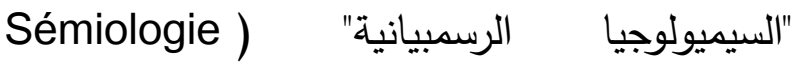
(Graphique Semiology of Graphics

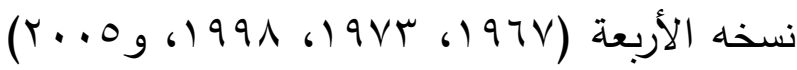
والمترجم إلى عدة لغات ( $9 \wedge v$ ( ) وأخيرا إلى العربية

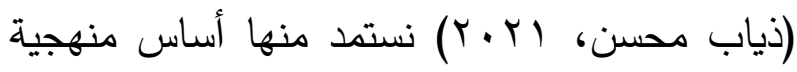

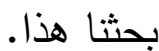


العقلية" (·9V ( ) ومنها الرسوم البيانية، وبين التثكيلات التوضيحية Figurations التي لا ترتقي إلى مستوى المقروئية النافذة الفعالة. وذكر أنه يجب لإبه تقييم الرسومات (الرسوم البيانية) بناءً على مفهوم الفعالية والكفاءة، وهو مفهوم مرتبط ارتباطًا وثيقًا

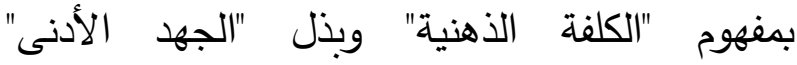
Théorie du moindre effort Least effort) (theory وقت ممكن لفهم الرسالة الرسومية المفيدة، والإجابة

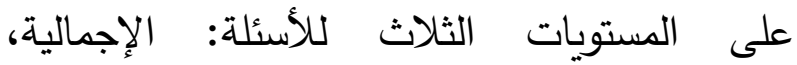

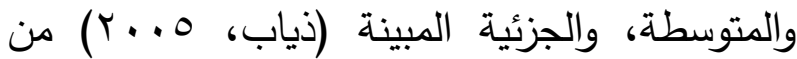
خلال الثكل التالي (الشكل ؟ج).
ولتتفيذ نظامه الرسميبياني، أعد بيرتين، بعد التمحيص والجدل والنقاش، أشكالا أو خطاطاتِ أساسية Schémas de base Basic schemes على معظم الأشكال الرسمبيانية المعروفة انطلاقا من درجة مقروئيتها وقدرتها على الرسوخ في الذاكرة، بعد أن قام بتجميعها وتبويبها وتصنيفها. ثم حاول ترتيبها

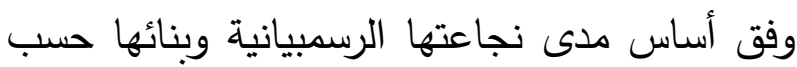
"نظرية الصورة" (Théorie de l'image Image theory والمستندات العامة والمستمدة منها، حيث كان يعتبر أن الرسم البياني، كغيره من الأثكال البيانية العقلانية،

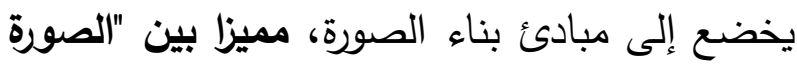

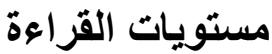
$X \cup A \exists \vee I n$
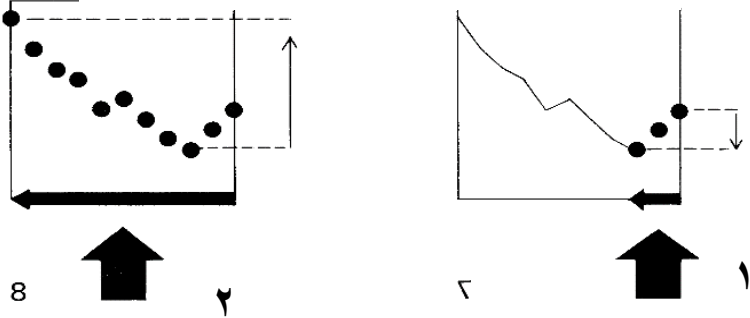

الثكل 7 يوضح المستويات الثلاث للقراءة من خلال منحنى بياني: في 1 المستوى الجزئي للقراءة والتركيز على جزئية من البيانات، وفي r المستويات البينية والاهتمام بجزء من المجموع، وفي ب المستوى الإجمالي والمقاربة التاليفية، وهو المستوى الأعلى. المصدر : (بيرتين،

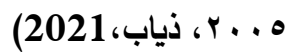

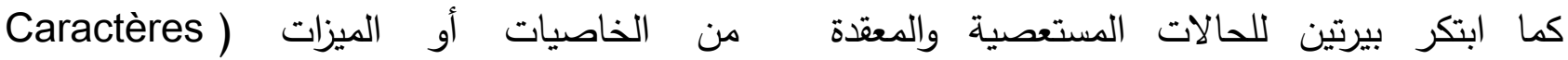
Characters للبيانات، مجموعة من الوسائل والطرائق للمعالجة (Objets Objects) بعض الاختيارات غير الصائبة، والتحيز لبعض أنواع والعرض، تقوم أساسا على البناء المصفوفي (Construction matricielle Matricial construction) (الأعمدة المكونة باعتماد نظام رسمبياني كامل متكامل، بداية بتجميع (permutation permutation) 
Matrice ) البيانات، ثم تحليلها، ثم عرضها وتبليغها للقارئ. الجزء (ع) المصفوفة الترتيبة

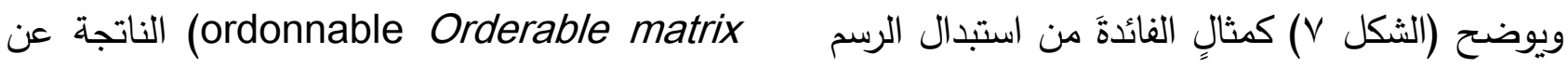
الدائري لفروع الأنشطة (حسب الزاوية بالدرجة لكل مُناقلة مدروسة ل للأسطر والأعمدة تُظهر أخيرا

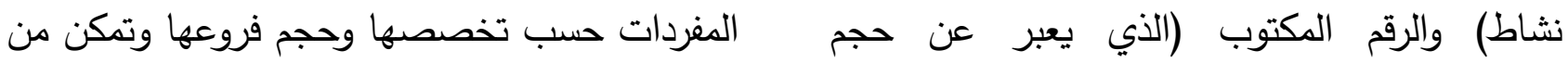

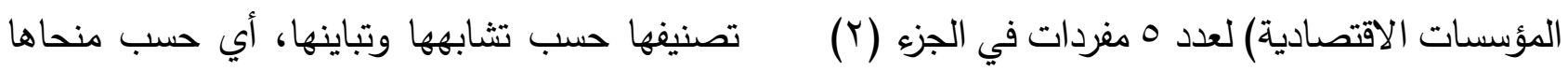
من الثكل، ببناءٍ مصفوفي متكامل ومنظمّ، يبين في البصري (Profil Profile).

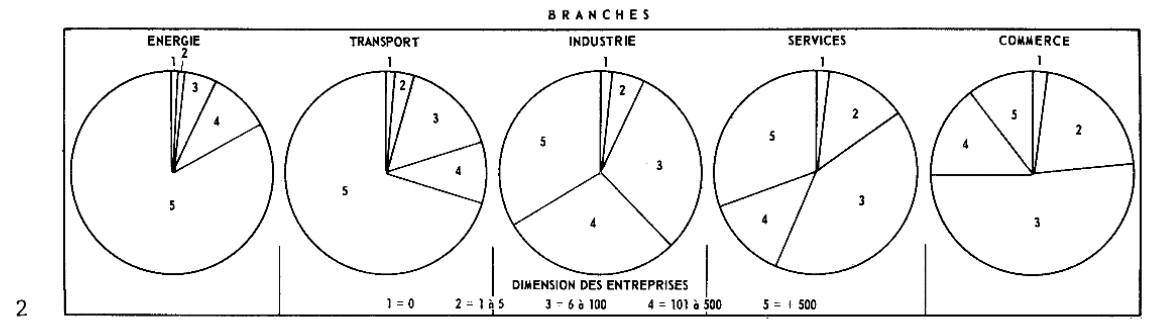

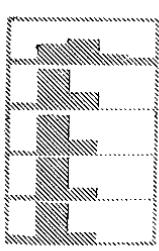

3

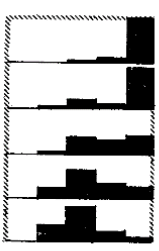

4

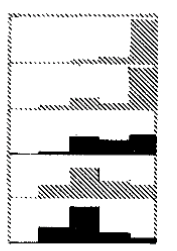

5

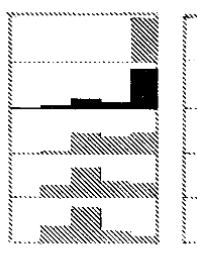

6

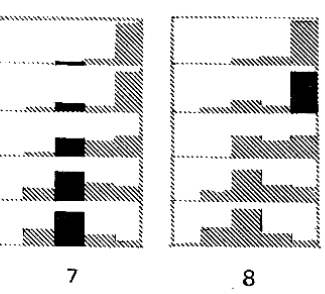

8

(الثكل V): يوضح الثكل كيفية استبدال الرسمبيانات الائرية القليلة الجدوى في المستوى الإجمالي للقراءة بالتحليل المصفوفي البانية

وباستذدام مبداً "التقطير" (أو الترتيب حسب المقطرة) لكي تُصنَف ألبياناثُ أسطرًا وصفوفًا. المصدر: (بيرتين، ه . . r وذياب، (r.r)

ونستعرض فيما يلي المخططات الأساسية لكل أنواع بعض العلاقات بين عناصره. أما الخرائط فهي تخضع

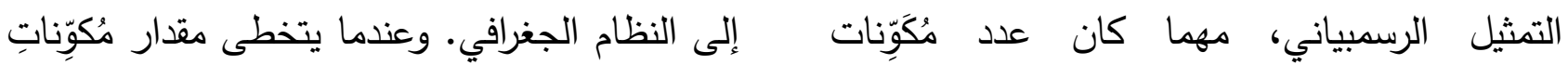
(البيانات، أي البيانات عدد بات تُستعمل الرسمبيانات الجردية (Composantes components)

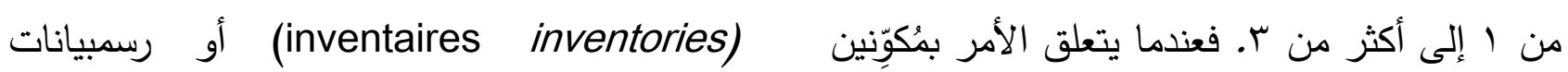

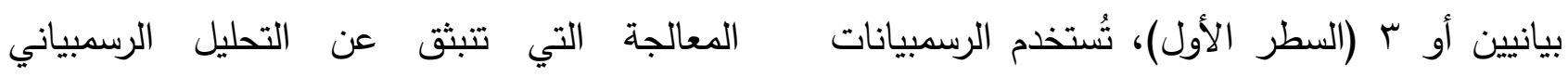

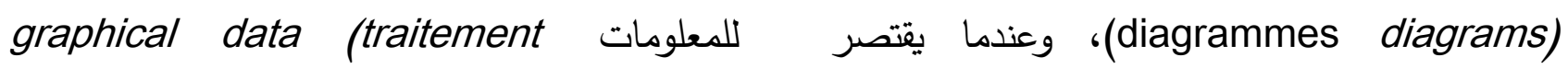

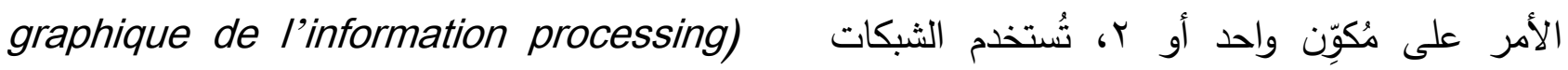

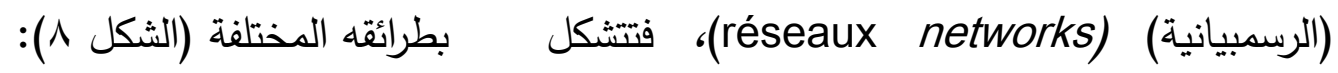




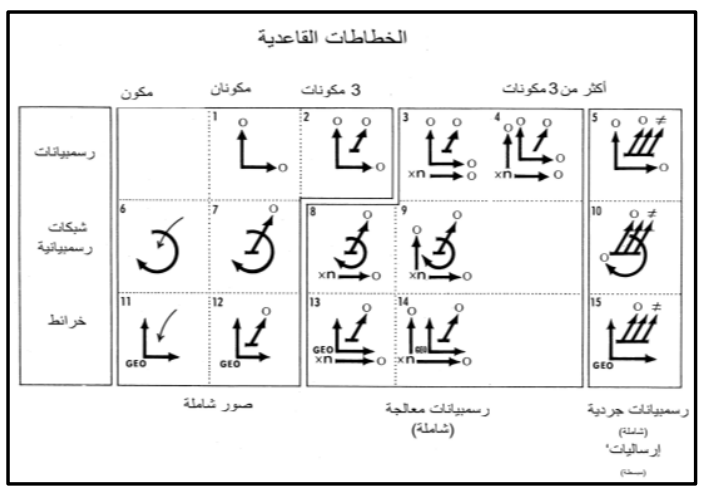

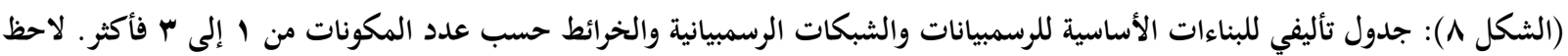

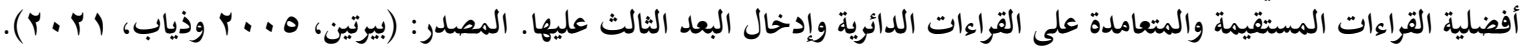
من خلال الشكل هذا، ُبرهَن بيرتين عن أفضلية إلى الأشكال الخاصة المستعصية للرسمبيانات بطريقة الأشكال المتعامدة لاستتادها إلى قاعدة مقارنة للبيانات أدق، بواسطة ما أطلق عليها الترتيب المصفوفي الممثَّة حسب المحور الأفقي والمحور الرأسي، وهو والتحليل الرسمبياني للمعلومات كما يظهر في (الثكل ما ينطبق على معاينتنا وتقديرنا للأحجام والأشكال في 9VV ( 9 ) ). حياتنا اليومية بشكل أيسر . كما حاول بيرتين التطرقَ مبر

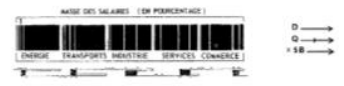

\section{(1900):}

$4<+\infty$

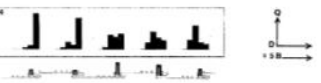

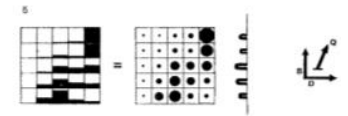

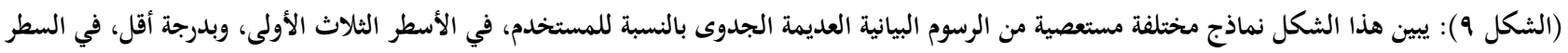

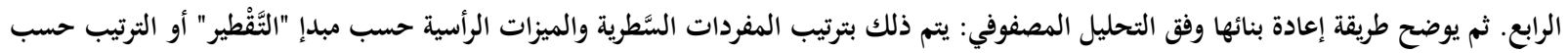

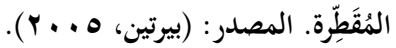


Sما أشار بيرتين إلى المستويات الأربعة لتنظيم والتناسبية (أو الكمية) البيانات (Proportionality $\quad$ Associativity

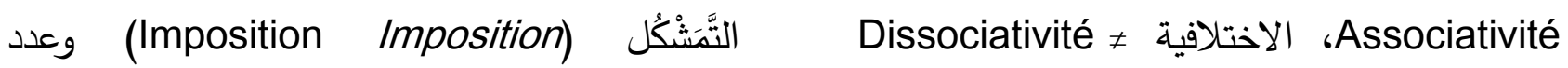
Associativity

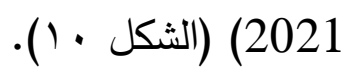

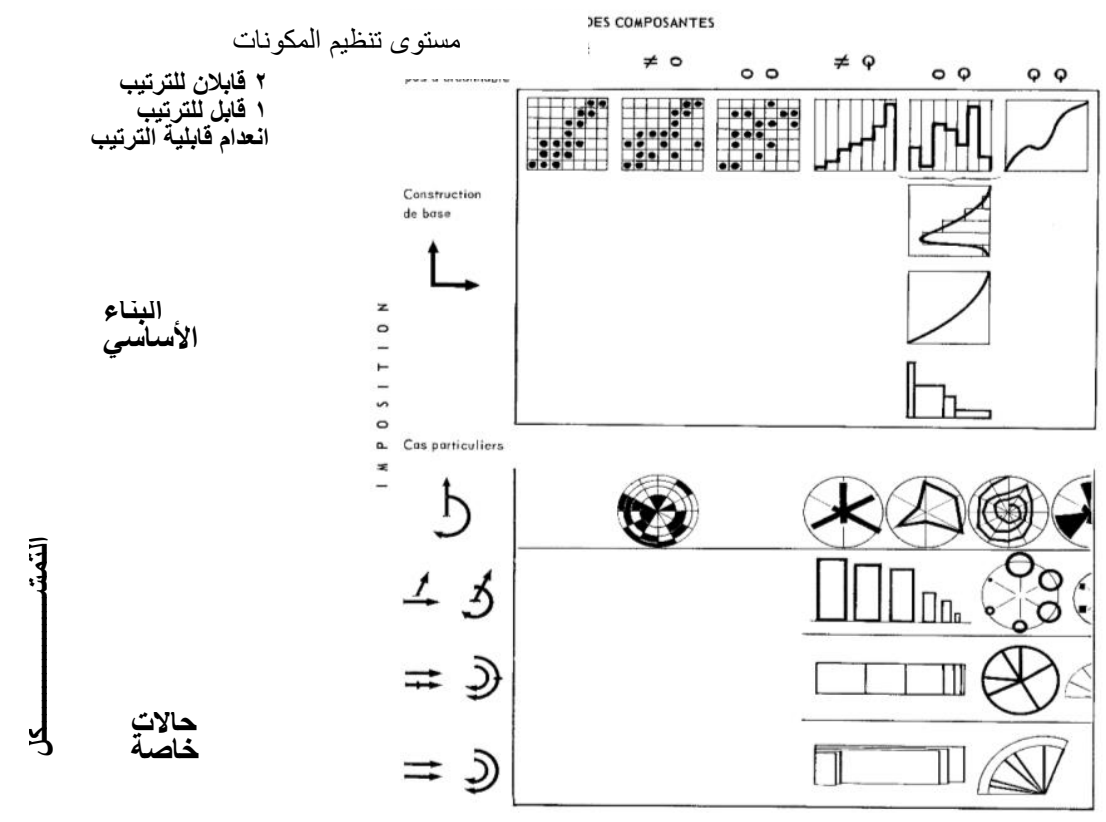

الثكل ا : مستويات تنظيم الدكونات حسب حالات التشكل الثلاثة: الرسمبيانات، والثبكات الرسمبيانية، والخرائط. المصدر: (بيرتين،

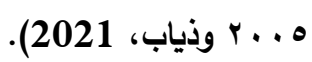

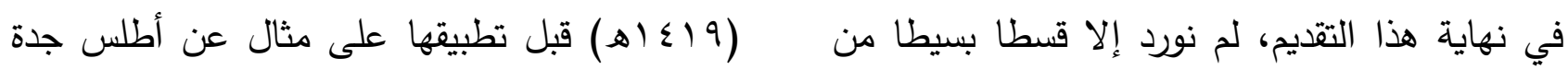
مُكونات النظام الرسمبياني الذي أسسه بيرتين. الرقمي.

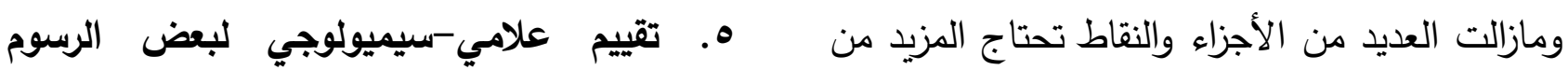

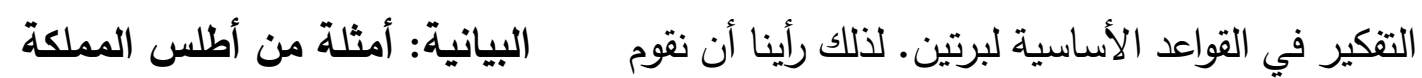

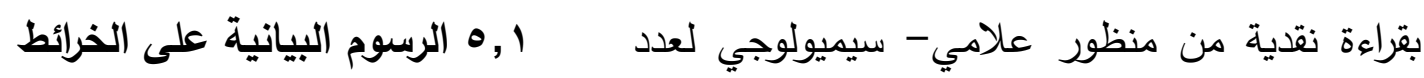
محدود من الرسوم البيانية الواردة في أطلس المملكة المثال الأول: من الثائع استخدام الرسوم الدائرية القطاعية المجزأة لبيان نسبة كل قطاع من المجموع. 
البيانات لأن الفوارق في زوايا القطاعين ضئيلةٌ جدا، فلا تسمح بإدراك واضح لها وعليه باستخلاص دلآلتها.

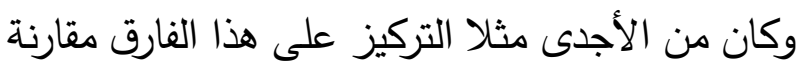

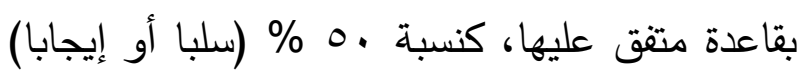

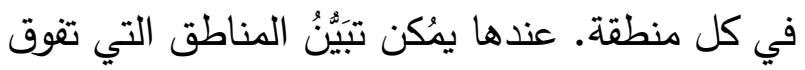

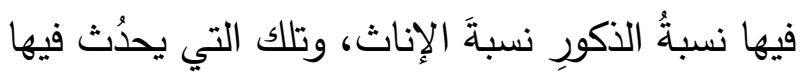

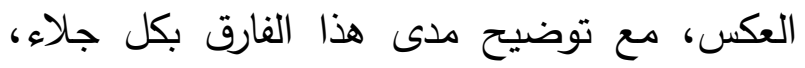

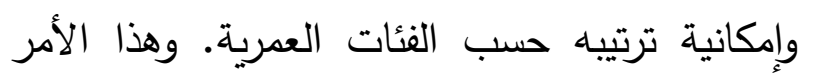

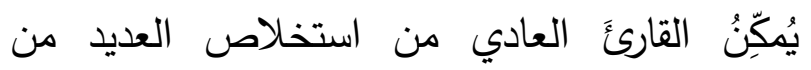
التحليلات وربما استشراف وتخطيط السياسة السكانية والديموغرافية المستقبلية.

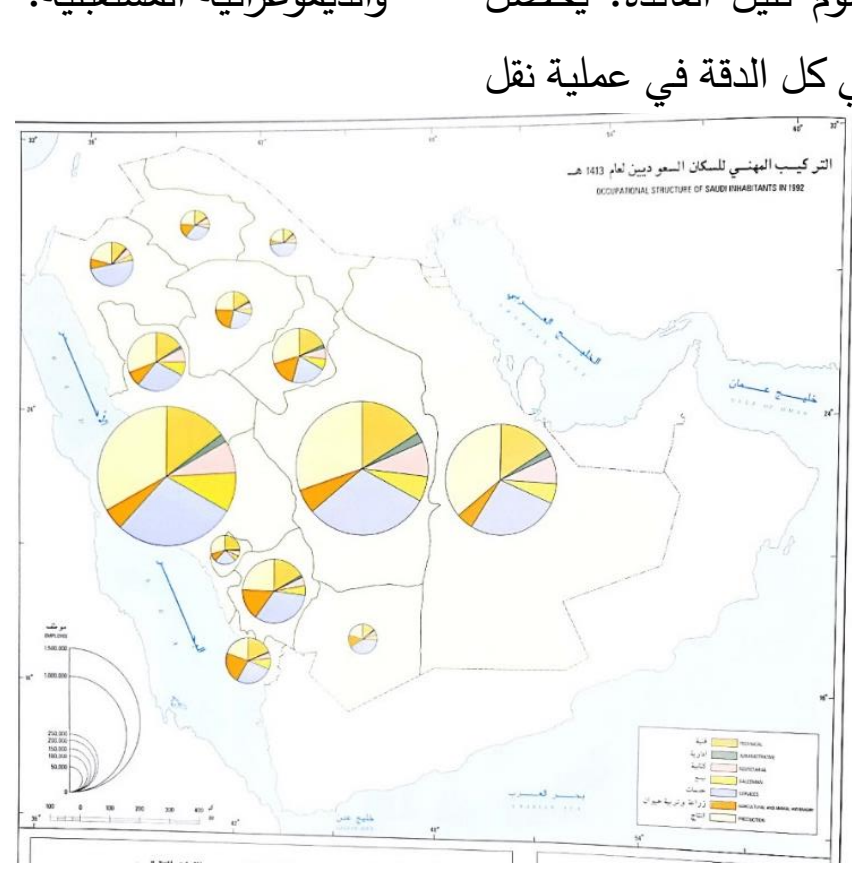

المثال الثاني: يتميز الرسم البياني بمقارنة للحالة الزواجية ب اء اهـ (ص. • ^) بالصفات التالية: قطاعان في شكل نصفي دائرة، نصف للذكور ونصف للإناث؛ هُكوِّنان كل منهما يحتوي عدة ألوان تبين الحالة الزواجية بصفة تصنية تراكمية؛ كما وضعت المناطق على محور ينطلق من المركز (القيمة · ) إلى محيط الدائرة (القيمة . . ( ).

وقد تبُينُ حالة الدراسة قطاعين أو أكثر، وكلما زاد عدد القطاعات استعصت الرؤيةُ والمقروئية، وكذلك الإدراكئ الإجمالي للصورة. وحتى في حالة وجود قطاعين فقط وبتوفر نسبة متقاربة بين القطاعين، كما هو الحال في خريطة التركيب المهني للسكان في مختلف مناطق المملكة (أطلس المملكة العربية السعودية، ص. (1)، تتقلص نسبة الاستفادة من مثل

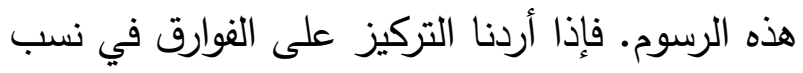
الإناث والذكور بين المناطق، وخاصة إذا اقترن الأمر التران

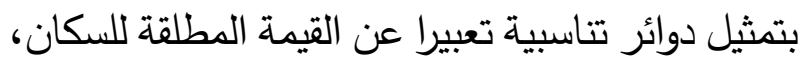
يصبح الحل بمثل هذه الرسوم قليل الفائدة. يحصل هذا حتى وإن توخى الخرائطي كل الدقة في عملية نقل

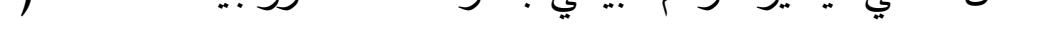




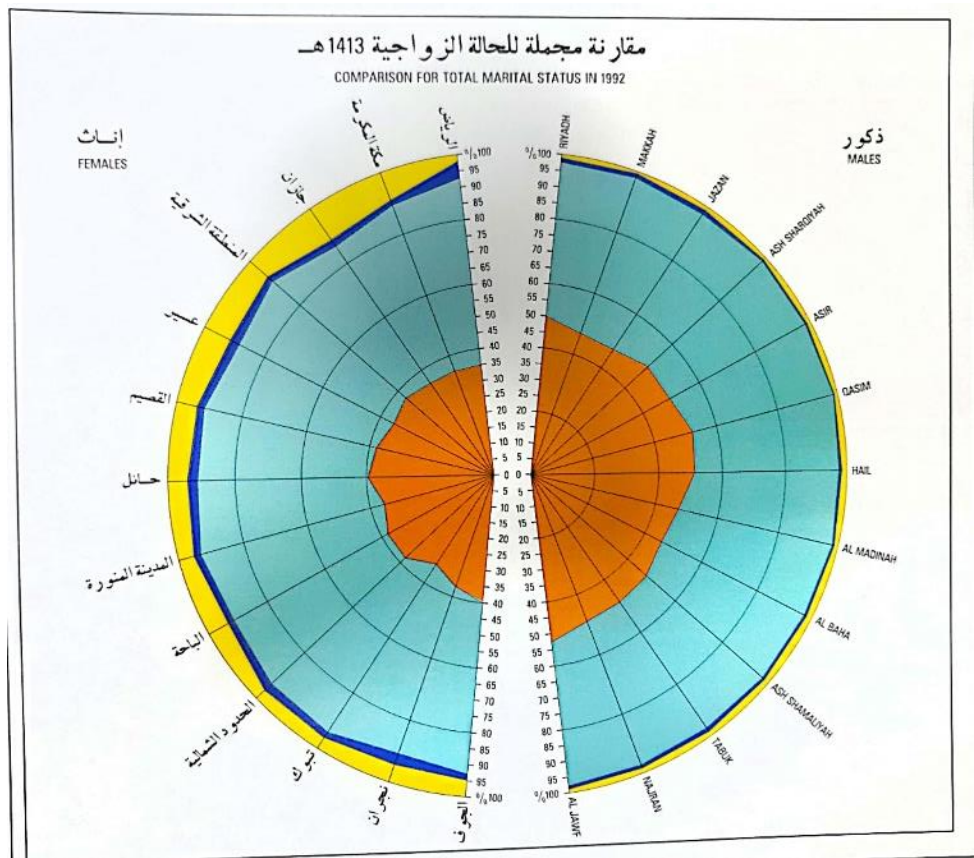

ولو وقع ترتيب المناطق حسب نسبة كل حالة لكان الأمر أيسر لتفادي صعوبة القراءة الدائرية.

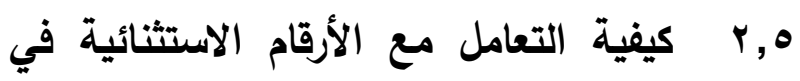
المتسلسلات الإحصائية

المثال الأول: من المتعارف عليه أنه لما توجد أرقام

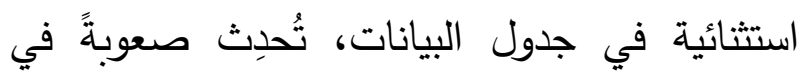

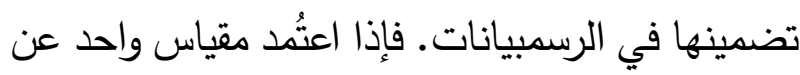

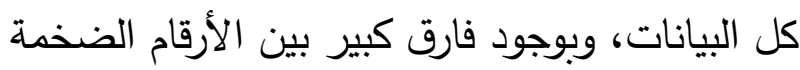

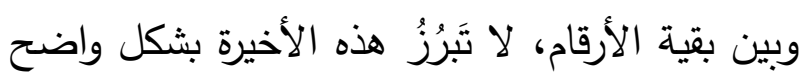
مهما كان المقياس وحجم وعاء الرسم، ولا يمكن لإن لإني

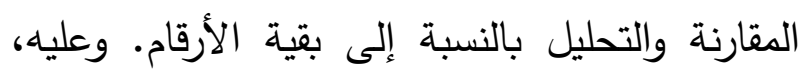
تصعب عملية المقارنة والاستيعاب لاى المستخدم. وهو أمر تغفل عنه جل المنتجات الرسمبيانية

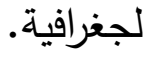

في المحصلة، وبمعاينة الألوان المعبرة عن كل فصيلة من الحالات الزواجية، تحصُلُ لدينا قراءةٌ خاطئة للألوان وحدودِها، أي بالمنْحى الذي يتخذه كل قطاع

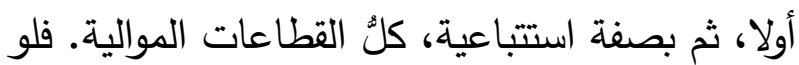

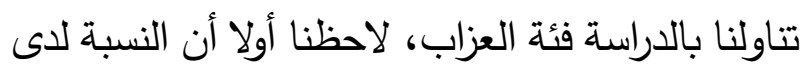

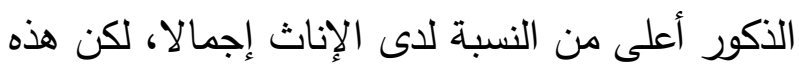
النسبة تختلف حسب المناطق. ولو وقع ترتيبُ المناطق حسب هذه النسبة، لكانت المعاينة أفضلَ بكثير، واستنتجنا نوعا من الأقَمَلَة الجغرافية الجديرة بالدراسة والتحليل. فيبدو أن تبوك ومكة وجازان وعسير التئرة والمدينة، أي المنطقة الغربية للمملكة، لها نسب ولب ضعيفة على عكس المناطق المتبقية. أليس هذا الأمز جديرا بالدراسة؟ المشكلة تكمن في صعوبة -إن لم نقل استعصاء- المقارنة بالنسبة إلى الحالات الزواجية الأخرى. ذلك أنها لا تقوم على ذات القاعدة الهندسية. 
والا \& اهـ، لا يُمَكِّن الرسم من القراءة السليمة إذا

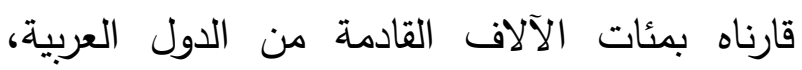
بالإضافة إلى أن الرسم بالأعمدة الثلاثي الأبعاد الأن الثاد

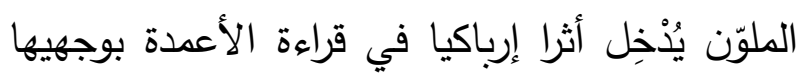
الرأسيين البارزين. ويَظهَر ذلك جليا أيضا في انعدام الترتيب في "نسب البردئ

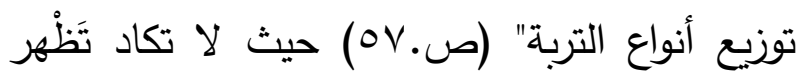
بعض الأنواع من الترب التي لا تبرز على الرسم

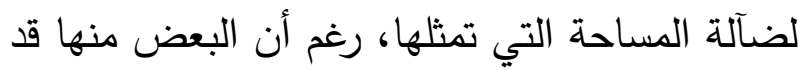
تكون له مردودية اقتصادية بالغة، ربما تفوق مردودية فصائل أخرى من الترب الممتدة المساحة.

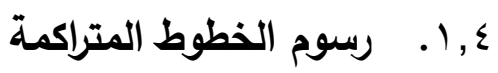
المثال الأول: يبين الثكل البياني تطور استهلاك

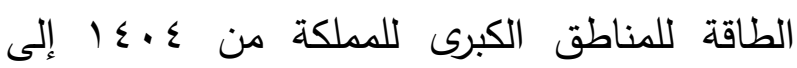

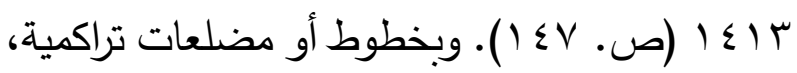
يظهر الخطُ البياني الأعلى للرسم وهو خط تصاعدي

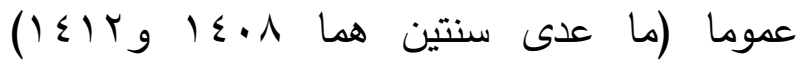
المجموعَ. كما إن الرَّسم يُبِيّن ضمنَه نصيبَ كل منطقة بدءا بالثمالية أسفل الرسم وانتهاء بالثرقية في القمة.

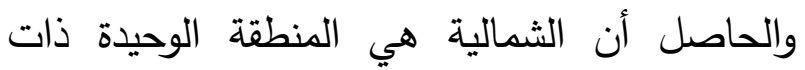
القاعدة الأفقية التي تُكِّن من بيان أنه، على عكس الته

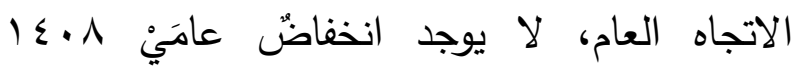

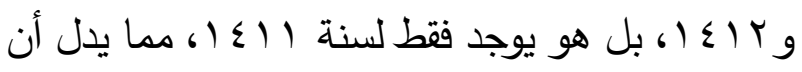
استهلالكَّ هذه المنطقة لم يكن مثل ما يحدث بالمملكة

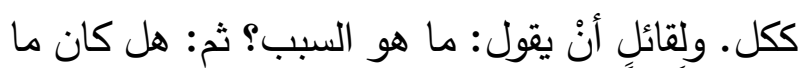

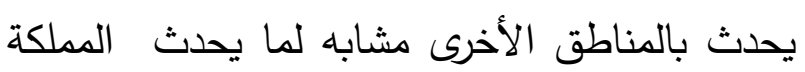

كما إن الأرقام الاستثنائية الضئيلة في حالة استخدام

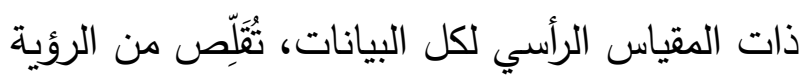

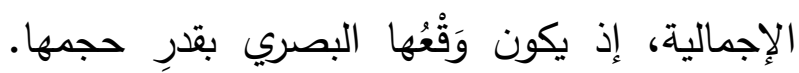

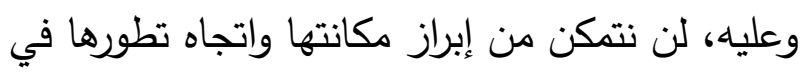
حالة ورود عنصر زمني. وقد تكون هذه العوامل مفيدة في استقراء التَّجهِ المستقبلي للظاهرة المدروسة. ويكمن الحلُّ المناسب، حسب الأبديات المتخصصة، في استخدام المقياس اللوغاريتمي بدلا من المقياس

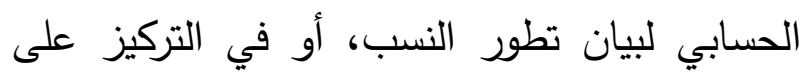

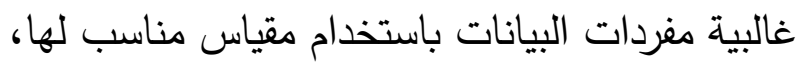

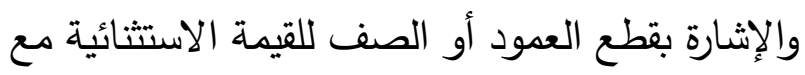

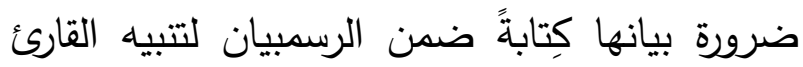
إليها. لكن الأمر الثابت هو أن استخدام أحد المقياسين الحسابي أو اللوغاريتمي دون الآخر يؤدي إلى إهمال جانب من جانبَيْ التحليل، باعتبار تركيز هذين

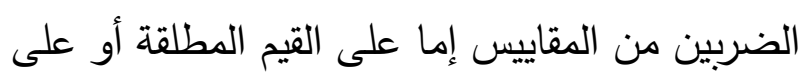

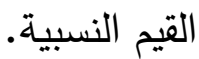

المثال الثاني: نرى أنه بالنسبة للقيم الصغرى، يمكن

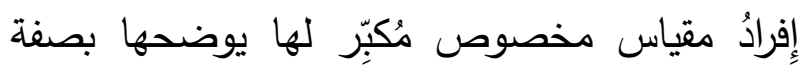
أجلى وأدق، مع ضرورة المحافظة عليها في الرسم الرئيس. وهذا ما كان يمكن القيام به في الرسم حول فيروة

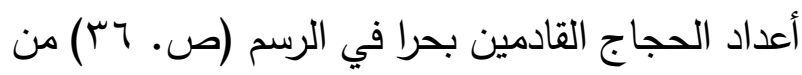

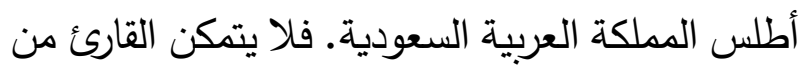
استجلاء تطور أعداد القادمين بحرا للحج. وفي الرسم حول أعداد المعتمرين القادمين من أوروبا وأمريكا حيث وفيث المريث

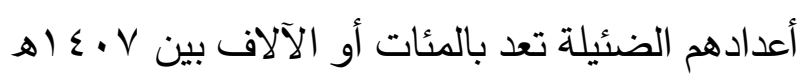


باستخدام طريقة من طرق التحليل الرسمبياني التي ابتكرها سابقا بيرتين والتي تعرضنا للبعض منها في بحوث سابقة (Dhieb, 1989; 1992; 1993). r. ب. الرسم حسب الأعداد المطلقة من الطبيعي أن تكون نقطة البداية لكل رسم بياني

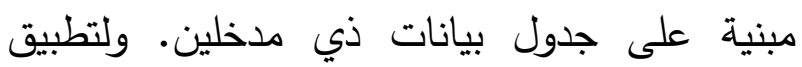
المقاربة السيميولوجية القائمة على زيلى ليادة إفادة المستخدم من الرسوم البيانية، نورد مثالا معقدا نوعا

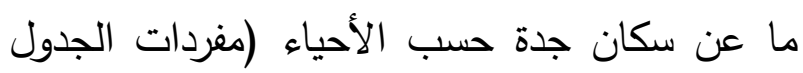
(table objects tableau des objets بين الإناث والذكور وبين السعوديين وغير السعوديين caractères du tableau table ميزات الجدول) (الجدول ()).
ككل؟ أم للمنطقة الشمالية وحدها؟ أم هو مختلف عنهما؟ وهل يوجد أصلا اختلاف بينها؟ كل هذه الأسئلة المشروعة لا تلقى إجابة لحظية من

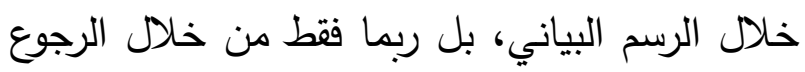
إلى ...جدول الأرقام!

والسبب بسيط: وهو أن الثكل التراكمي لا يتيح

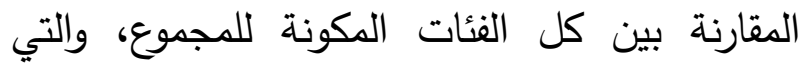
تقتضي أن تكون قاعدةٌ ثابتة غير متغيرة لإجراء

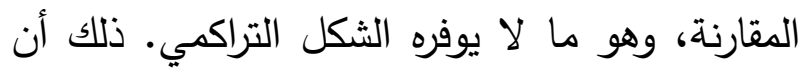
قاعدة كل منطقة لا تمثل خطا أفقيا، بل خطا معوجًا

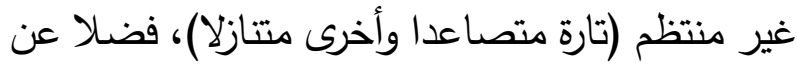
كون اعوجاجه وعدم انتظامه يختلفان من منطقة إلى

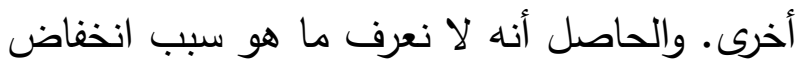
استهلاك الطاقة في المملكة وما هي أكثر المناطق

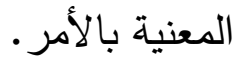

وفي تقديرنا تكمن المشكلة في الرغبة في تجميع كل البيانات المفصلة في رسم واحد. ولكي يكون العمل مُقِنِعا، يمكن استخدام ذات المساحة لهذا الرسم وتقكيك البيانات: سوف يُستتنج أنه توجد إجابة ممكنة عن كل التساؤلات المشروعة والمطروحة والتي لم تتلق ردا مقنعا. وهذا ما سنحاول بيانه من خلال مثال عن أطلس جدة الرقمي.

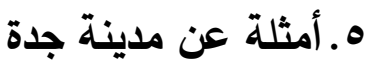
لابد من تتبيه القارئ أننا اخترنا عنوة مثالا متعدد البيانات وحاولنا إجراء رصد شمولي لكل الخطوات الواجبة اتباعها للوصول إلى صورة رسمبيانية 
الجدول ا : سكان مدينة جدة حسب الأحياء والجنس والسكان السعوديين وغير السعوديين

\begin{tabular}{|c|c|c|c|c|c|c|c|c|c|c|}
\hline \multicolumn{10}{|c|}{ سكان ومساكن جدة حسب الأحياء } & \\
\hline \multicolumn{3}{|c|}{ مجموع السكان } & \multicolumn{3}{|c|}{ غير السعوديين } & \multicolumn{3}{|c|}{ السعوديون } & \multirow[b]{2}{*}{ المساكن } & \\
\hline المجموع & إناث & ذكور & المجموع & إناث & ذكور & المجموع المجوع & إناث & ذكور & & \\
\hline 48696 & 15245 & 33451 & 42064 & IrTh & ห१ะ४ч & 6632 & ryוV & $\{\cdot 10$ & $1 r \leq 70$ & البلد \\
\hline 47314 & 19367 & 27947 & 36964 & $1 \leq \leqslant 79$ & $r Y \leq 90$ & 10350 & $\varepsilon \wedge 9 \wedge$ & $0 \leqslant 0 r$ & 111790 & المنداوية - ماية \\
\hline 21924 & 8874 & 13050 & 13889 & $0 . .0$ & $\wedge \wedge \wedge \leq$ & 8035 & r人тq & $\{174$ & 1010 & الثعالبة \\
\hline 39560 & 15966 & 23594 & 25378 & $91 . r$ & ITrVo & 14182 & אזדי & VTI & 9410 & بترومين \\
\hline 12153 & 811 & 11342 & 11835 & $v \cdot 7$ & $111 \times 9$ & 318 & 1.0 & זाT & 纟八广 & 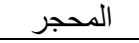 \\
\hline 17551 & 5815 & 11736 & 8563 & $10 \mathrm{re}$ & $V \cdot r_{0}$ & 8988 & $\varepsilon r V V$ & 纟vו1 & 1rkq & 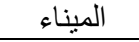 \\
\hline 11820 & 3759 & 8061 & 4848 & $r \cdot r$ & $\{0 \leq 7$ & 6972 & $r \leqslant 0 V$ & ro10 & rll. & 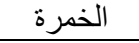 \\
\hline 3111 & 562 & 2549 & 2098 & $\leq V$ & $r .01$ & 1013 & 010 & $\sum 9 \wedge$ & VV. & المستودعات \\
\hline 715 & 3 & 712 & 668 & r & דצד & 47 & 1 & $\leq 7$ & $r \leqslant \varepsilon$ & الصناعية \\
\hline 5419 & 2514 & 2905 & 1051 & $r q$. & 771 & 4368 & rMr & $r Y \leq \varepsilon$ & $9 \wedge \vee$ & جو هرة جدة \\
\hline 40756 & 18225 & 22531 & 7456 & ।Vq & זדוד & 33300 & $17 \leq \pi 1$ & 17149 & $7 \wedge \leqslant 9$ & الإنوبي \\
\hline 65555 & 29409 & 36146 & 14226 & $\varepsilon \cdot$ & $1 \cdot(1 \leq$ & 51329 & orav & ro9rt & $11 \vee \vee \wedge$ & الأمير فواز \\
\hline 73861 & 32853 & 41008 & 30276 & $11 \mathrm{VIV}$ & 11009 & 43585 & דrונו & $r Y \leq \leqslant 9$ & |וזדו & كيلو ع 1 \\
\hline 26762 & 12786 & 13976 & 4146 & 1004 & roqr & 22616 & אזr & IITAK & $\varepsilon r V \tau$ & كيلو 11 \\
\hline 18380 & 8939 & 9441 & 1955 & 1.7 & $11 \leqslant 9$ & 16425 & 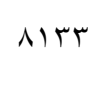 & Arqr & 「人१〉 & $\begin{array}{l}\text { الثنتز هية } \\
\text { الثتية }\end{array}$ \\
\hline 31732 & 14936 & 16796 & 3737 & 1057 & 2680 & 27995 & 13879 & 14116 & 4821 & الشرقية بات \\
\hline 63164 & 29247 & 33917 & 10433 & $r \leqslant r_{0}$ & 7991 & 52731 & rONIT & r7919 & $111 r 9$ & قويزة \\
\hline 27992 & 13889 & 14103 & 6734 & r191 & ros & 21258 & 1.791 & 1.07. & OVTV & السليمانية \\
\hline 83473 & 38091 & 45382 & 24903 & qTVY & 10041 & 58570 & rAVIq & rq^ol & $17 . r A$ & الروابي \\
\hline 133790 & 55840 & 77950 & 78206 & TlAr & $\varepsilon V \cdot r \varepsilon$ & 55584 & $r \leq 70 \wedge$ & $r .9 r \tau$ & $r .9 r v$ & الجامعة \\
\hline 91069 & 34380 & 56689 & 41628 & $10 r 70$ & אדצזי & 49441 & 19110 & T.rTt & $I V V \cdot r$ & مدائن فهر \\
\hline 121 & 0 & 121 & 81 & - & 11 & 40 & · & $\varepsilon$. & $\varepsilon$ & الوزيرية \\
\hline 65821 & 27338 & 38483 & 32141 & 1.179 & TIYVY & 33680 & $17 \leq 79$ & $\mid V Y \|$ & $1 \leqslant r \neg 1$ & غليل \\
\hline 15095 & 6921 & 8174 & 7351 & riov & $\leq 19 \leq$ & 7744 & TVTE & rqA. & TrTV & القريات \\
\hline 56977 & 26383 & 30594 & 28670 & $1 r \leqslant 01$ & $1741 \%$ & 28307 & 1raro & $1 \leqslant T \wedge T$ & ITYAY & اليمانية \\
\hline 17248 & 4920 & 12328 & 8656 & 0 & A. & 8592 & סדז & EYOV & 0.90 & الثرقية \\
\hline 41462 & 17708 & 23754 & 28227 & $11 \leq 1 \leq$ & T171 & 13235 & 7イ & $79 \leqslant 1$ & 997. & الثغر \\
\hline 32370 & 13880 & 18490 & 16962 & 7195 & $1 \cdot V V$. & 15408 & $\vee \vee \neg \Lambda \Lambda$ & VVY. & $7 \leqslant \vee q$ & الفيحاء \\
\hline 43999 & 18435 & 25564 & 36189 & $1 \leqslant 1.0$ & YITیE & 7810 & . זדז. & 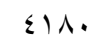 & 1.047 & الكندرة \\
\hline 26205 & 11026 & 15179 & 19708 & $\Lambda . \leq 0$ & אד7711 & 6497 & rqA1 & ro17 & 09.1 & السبيل \\
\hline 19291 & 6404 & 12887 & 17486 & 0V79 & IIVIV & 1805 & סזו & $11 \mathrm{~V}$. & 0097 & الصحيفة \\
\hline 14146 & 5549 & 8597 & 11987 & $\leqslant O V$. & $V \leqslant । V$ & 2159 & q४q & 111. & rorq & العمارية \\
\hline 23586 & 8358 & 15228 & 19973 & $7 V^{6}$ & IMIAr & 3613 & 07 & r. & TV9V & الثغدادية \\
\hline 12190 & 4598 & 7592 & 9662 & rol & 4זוד & 2528 & 1.74 & $1 \leq 77$ & $r .70$ & الغخدادية \\
\hline 49718 & 20298 & 29420 & 33167 & Tr & 1 & 16551 & $N$ & $\Lambda \varepsilon$ & i Tro. & جزء من \\
\hline 57228 & 22544 & 34684 & 39392 & $1 \leq 111$ & YOYAl & 17836 & $\Lambda \leqslant \Psi T$ & $9 \leq . r$ & $10 \leqslant 11$ & الثرفية \\
\hline 6072 & 2691 & 3381 & 4259 & $1 \wedge \Lambda \varepsilon$ & rrVo & 1813 & $\Lambda \cdot V$ & $1 \ldots 7$ & 1011 & الورود \\
\hline
\end{tabular}


محسن الهادي ذياب وعبد الحميد محمد جميل ومحمد عوض العمري

\begin{tabular}{|c|c|c|c|c|c|c|c|c|c|c|}
\hline 30420 & 14562 & 15858 & 6561 & rqाr & גו דצ & 23859 & $117 \leqslant 9$ & $|r r|$. & $V \leqslant T Y$ & النسيج \\
\hline 69685 & 23671 & 46014 & 41501 & 1.101 & mito. & 28184 & iror. & $1 \leq 77 \varepsilon$ & 17411 & بني مالك \\
\hline 18208 & 5094 & 13114 & 10279 & $1 \leqslant r$ & $\Lambda \Lambda \leqslant \varepsilon$ & 7929 & $r 709$ & $\varepsilon r V$. & rTrq & وريخام \\
\hline 19978 & 8361 & 11617 & 4963 & $9 \wedge \varepsilon$ & एवv & 15015 & VTVV & VITA & TrV & التوفيق وأم \\
\hline 56925 & 25345 & 31580 & 13053 & ror & 901 & 43872 & ris & $r Y$. & ᄉ $94 \wedge$ & و الأجواد \\
\hline 25174 & 10761 & 14413 & 5880 & $1 K 17$ & 纟Tา & 19294 & $90 \leqslant 0$ & $9 \vee \leqslant q$ & STr & بريمان \\
\hline 5958 & 407 & 5551 & 5026 & VV & $\leq 9 \leq 9$ & 932 & rr. & 7. & $1 \cdot 1 \varepsilon$ & بريمان \\
\hline 21068 & 7892 & 13176 & 15682 & $O V \leqslant \Lambda$ & $99 \% \leqslant$ & 5386 & $r) \leq \varepsilon$ & $r T \leqslant r$ & $1 \pi \leqslant r$ & المطار \\
\hline 55155 & 21369 & 33786 & 19480 & $\leqslant r \leqslant 0$ & lorto & 35675 & WVIYE & 11001 & $9 r \leqslant r$ & المروة \\
\hline 188027 & 86463 & 101564 & 64301 & rutov & rVq & 123726 & 7.1 .7 & . & $\varepsilon r V Y V$ & الصفا \\
\hline 41100 & 18722 & 22378 & 18154 & Voor & $1.7 . r$ & 22946 & 1118. & $118 \times 4$ & $9 \leqslant 9 \vee$ & الرحاب \\
\hline 94700 & 39091 & 55609 & 67456 & TTYAT & $\varepsilon \| V \varepsilon$ & 27244 & $1 Y \wedge .9$ & $1 \leq \leqslant r_{0}$ & rorrt & مشرفة \\
\hline 21770 & 9446 & 12324 & 12072 & $\sum V 07$ & VTIT & 9698 & $\leqslant 79$. & $0 \cdots 1$ & $0 V 00$ & الحمر اء \\
\hline 16159 & 7640 & 8519 & 6072 & r... & $r \cdot V r$ & 10087 & $\leqslant 7 \leqslant$. & $0 \leqslant \leqslant V$ & TVIT & الأندلس \\
\hline 114680 & 44182 & 70498 & 83688 & rqA.V & orsul & 30992 & $1 \leqslant r V_{0}$ & $1771 \mathrm{~V}$ & rqovV & العزيزية \\
\hline 87821 & 36376 & 514 & 51784 & I9YTr & MTOYY & 36037 & $|V| \mid \leq$ & 1А9rT & Yrq৭ะ & الفيصلية \\
\hline 50761 & 22509 & 28252 & 27323 & $11.9 \mathrm{~V}$ & $17 Y Y 7$ & 23438 & 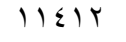 & Ir.r. & DTMT & الروضة \\
\hline 14457 & 7519 & 6938 & 10545 & 070. & $\leqslant 190$ & 3912 & 1179 & $r \cdot \leqslant r$ & ro14 & الخالدية \\
\hline 28440 & 11948 & 16492 & 12916 & $\{107$ & AVT. & 15524 & VVQY & VVTT & $\leqslant 7 \wedge 7$ & الثشاطئ \\
\hline 37504 & 18254 & 19250 & 15071 & 7101 & ATIT & 22433 & 11199 & $11 . r V$ & N10r & الز هر اء \\
\hline 69538 & 29248 & 40290 & 35751 & $\mid r \cdot Y \Lambda$ & TYVTT & 33787 & ITKY. & IVOTV & $191 . r$ & السلامة \\
\hline 73542 & 30690 & 42852 & 39094 & $1 \leqslant T r V$ & $r \leqslant V T V$ & 34448 & תדוזי1ד & 11.10 & T.VTr & البو ادي \\
\hline 131718 & 52573 & 79145 & 55463 & 10774 & rqA. 1 & 76255 & r7911 & एवा & rव५वा & الربوة \\
\hline 75898 & 31061 & 44837 & 28783 & $N|r|$ & r.TTY & 47115 & rrqs. & $r \leq 1 V_{0}$ & IVIVY & النز هة \\
\hline 28152 & 13388 & 14764 & 8405 & 4701 & $\leq V 0 \leqslant$ & 19747 & QVTV & $1 \ldots 1$ & OVqV & النعيم \\
\hline 28400 & 13376 & 15024 & 8211 & TYAq & EqT & 20189 & $1 \ldots \lambda v$ & $1.1 . r$ & 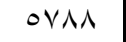 & النهضة \\
\hline 26814 & 13388 & 13426 & 4046 & rito & 1911 & 22768 & llror & 11010 & $\varepsilon r q \Lambda$ & المحمدية \\
\hline 9421 & 4681 & 4740 & 1849 & אדפ & 917 & 7572 & $r V \leqslant \Lambda$ & TAYs & 101. & البساتين \\
\hline 9369 & 4080 & 5289 & 3004 & $9 \vee r$ & $r \cdot r$ & 6365 & 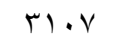 & rron & 11.1 & المرجان \\
\hline 2408 & 469 & 1939 & 1743 & $1 \wedge$ & 107 & 665 & rAT & rvq & $\wedge 1$ & الجنوبية \\
\hline 3714 & 516 & & 31 & $r$ & r & 606 & 1 & r99 & 1 & أشمالية \\
\hline 4004 & 1397 & 2607 & 1496 & rIT & IrAT & 2508 & 1184 & 1324 & 979 & الرحيلي \\
\hline 307294 & 1173043 & 34251 & 1367729 & 481844 & 885885 & 1439565 & 691199 & 748366 & 615403 & المجموع \\
\hline
\end{tabular}

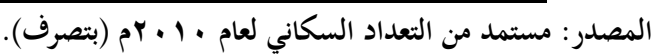

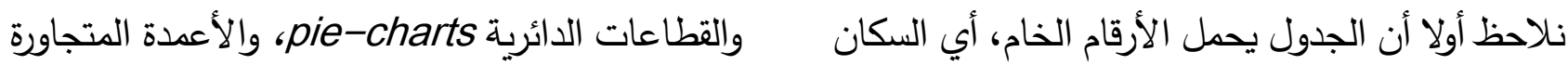
السعوديين وغير السعوديين بجدة، إناثا وذكورا وحسب وغيرها من الرسوم الكثيرة التي توفرها البرمجيات الأحياء، بالإضافة إلى عدد المساكن بكل حي. مبدئيا، المتخصصة كإكسل Excel. لكن كما قلنا سابقا، تتوفر عدة حلول للتمثيل البياني لكل البيانات مجتمعة، واستتادا إلى نظرية بيرتين حول المقروئية الضعيفة منها الأعمدة (أو الصفوف) المتراكبة (أو المجزأة)، التي توفرها العديد من الأشكال البيانية المبنية على 


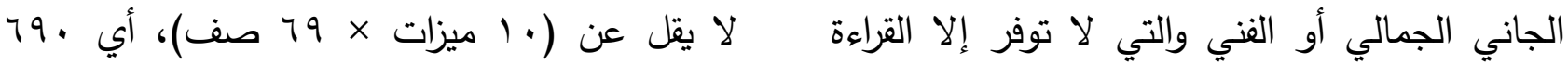

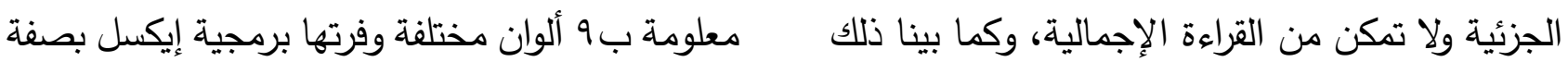
سابقا من خلال بعض الأمثلة من أطلس المملكة، عشوائية، وبطول مختلف يعبر عن عن عدد السكان.

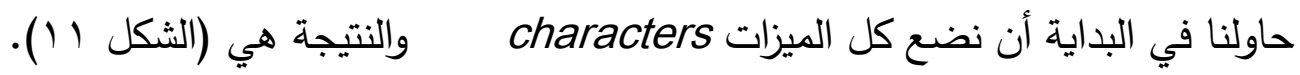

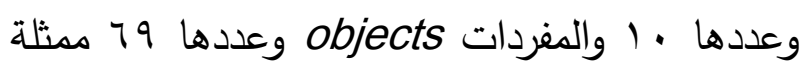
بأحجامها الحقيقية ووفق قاعدة مقارنة موحدة وهي المحور الرأسي الممثل للصفر كقاعدة لكل عمود. هذا الإجراء أدى إلى رسم بياني بالصفوف (بدل الأعمدة

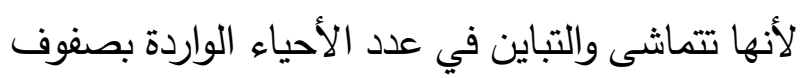

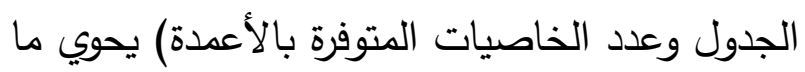

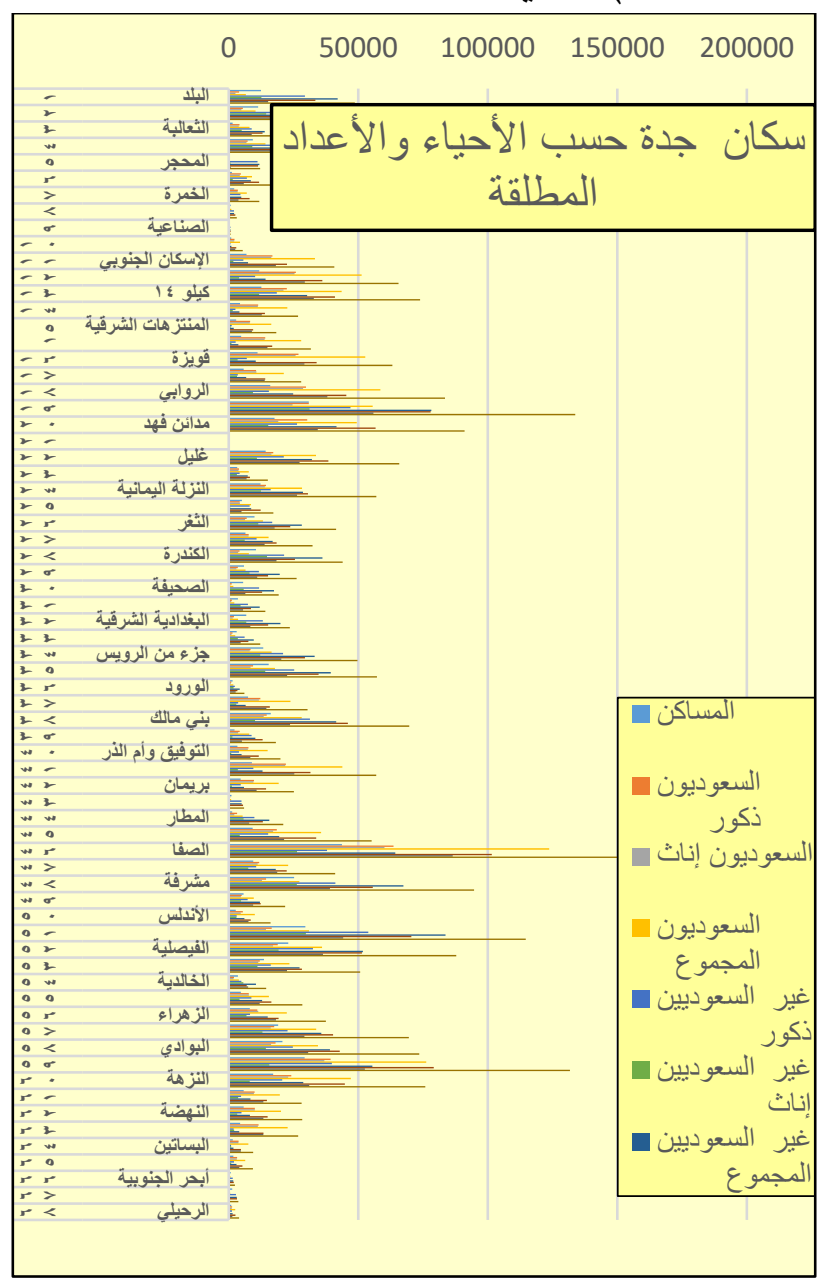

الثكل 1 1: رسم بياني لأعاد سكان أحياء جدة حسب الجنس والجنسية والمجموع كما وردت بالجدول |. المصدر تعداد ـ 1 ـrم. 


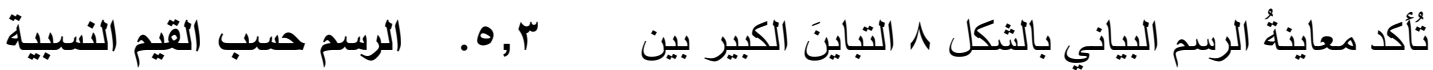
الأحياء، وبخاصة الأحياء ذات الأرقام الاستثنائية وفي خطوة أولى تمهيدية لحل هذا الإشكال، وحسب الأمثلة الرائجة المعمول بها في معظم رسائل البحث، عادة ما يُستبدل الجدول ا بالأعداد المطلقة بجدول نسب مئوية، فيُمنَّل كل حي بنسبته المئوية من مجموع ما: الإناث أو الذكور، السكان السعوديون وغير السعوديين، أي حسب المجموع آخر كل سطر • وهذا ما قمنا به بدايةً في الجدول ب، حيث أصبح مجموع كل حي من الأحياء وكل ميزة من الميزات يمثل • . . . (الجدول Y). وقد استثنينا منه عمود المساكن بصفة مؤقتة لأنها ميزة غير مفصلة حسب فئات كحي الصفا وحي الربوة وحي العزيزيـة التي تبرز بشكل مثير، وهو أمر معروف ومتوقع نظرا لارتفاع أعدادها السكانية. لكن نعتقد أن مهمة الرسم البياني أعمق من التوقف عن معاينة الأرقام المطلقة، ومن ذلك: محاولة التعرف على التوزيـع الداخلي للفئات السكانية عن كل حي، ومحاولة تجميع الأحياء وتصنيفها إلى مجموعات، وتباين الأحياء من حيث الفوارق في نسب السعوديين وغير السعوديين، ونسب الإناث والذكور • ويتطلب هذا الأمر أولا تَسويةَ المجموع، وهو أمر مستعص حتى على الخبراء والمهنيين، مما يجعل الدراسة. العودة إلى جدول الأرقام أمرا إلزاميا.

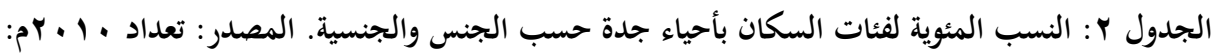

\begin{tabular}{|c|c|c|c|c|c|c|c|c|c|c|}
\hline \multicolumn{3}{|c|}{ مجموع السكان } & \multicolumn{3}{|c|}{ غير السعوديين } & \multicolumn{3}{|c|}{ السعوديون } & \multirow[b]{2}{*}{ الحي } & \multirow[b]{2}{*}{ الم } \\
\hline المجموع & إناث & ذكور & | المجموع & | إناث & |ذكور & المجموع & إناث & ذكور & & \\
\hline $\begin{array}{r}100.00 \\
\%\end{array}$ & $31.31 \%$ & $68.69 \%$ & $86.38 \%$ & $\%$ ro,qr & $\% 7,, \leq 0$ & $13.62 \%$ & $\% 0, r v$ & $\% \wedge$, Y० & البلد & 1 \\
\hline $\begin{array}{r}100.00 \\
\%\end{array}$ & $40.93 \%$ & $59.07 \%$ & $78.12 \%$ & $\% \mu \cdot, 0 \wedge$ & $\% \leqslant V, 0 \leqslant$ & $21.88 \%$ & \% & $\% 11,0 r$ & الهنداوية & 2 \\
\hline $\begin{array}{r}100.00 \\
\%\end{array}$ & $40.48 \%$ & $59.52 \%$ & $63.35 \%$ & $\% r r, \wedge r$ & $\% \varepsilon \cdot, o r$ & $36.65 \%$ & $\% \backslash \vee, 70$ & $\% 19, \ldots$ & الثعالبة & 3 \\
\hline $\begin{array}{r}100.00 \\
\%\end{array}$ & $40.36 \%$ & $59.64 \%$ & $64.15 \%$ & $\% r r, .1$ & $\%\{1,1 \leq$ & $35.85 \%$ & $\% \backslash \vee, r o$ & $\% \backslash \wedge, 0$. & بترومين & 4 \\
\hline $\begin{array}{r}100.00 \\
\%\end{array}$ & $6.67 \%$ & $93.33 \%$ & $97.38 \%$ & $\% 0, \wedge 1$ & $\% 91,0 \mathrm{~V}$ & $2.62 \%$ & $\% \cdot, \wedge т$ & $\% 1$, , & المحجر & 5 \\
\hline $\begin{array}{r}100.00 \\
\%\end{array}$ & $33.13 \%$ & $66.87 \%$ & $48.79 \%$ & $\% \wedge, \vee \uparrow$ & $\% \varepsilon \cdot, \cdot r$ & $51.21 \%$ & $\% r \varepsilon, r v$ & $\% r \neg, \wedge \varepsilon$ & الميناء & 6 \\
\hline $\begin{array}{r}100.00 \\
\%\end{array}$ & $31.80 \%$ & $68.20 \%$ & $41.02 \%$ & $\% r, 00$ & $\% \sqcap \wedge, \leq\rceil$ & $58.98 \%$ & $\%$ \% , ro & $\% \curlyvee q, \vee \leq$ & الخمرة & 7 \\
\hline $\begin{array}{r}100.00 \\
\%\end{array}$ & $18.06 \%$ & $81.94 \%$ & $67.44 \%$ & $\% 1,01$ & $\% 70,94$ & $32.56 \%$ & $\% 17,00$ & $\% 17, .1$ & المستودع & 8 \\
\hline $\begin{array}{r}100.00 \\
\%\end{array}$ & $0.42 \%$ & $99.58 \%$ & $93.43 \%$ & $\% \cdot, \uparrow \wedge$ & $\% 94,10$ & $6.57 \%$ & $\% \cdot, 1 \leq$ & $\% 4, \varepsilon r$ & الصناعية & 9 \\
\hline
\end{tabular}


100.00 $\%$ 100.00 $\%$ 100.00 $\%$ 100.00 $\%$ 100.00 $\%$ 100.00 $\%$ 100.00 $\%$ 100.00 $\%$ 100.00 $\%$ 100.00 $\%$ 100.00 $\%$ 100.00 $\%$ 100.00 $\%$ 100.00 $\%$ 100.00 $\%$ 100.00 $\%$ 100.00 $\%$ 100.00 $\%$ 100.00 $\%$ 100.00 $\%$ 100.00 $\%$ 100.00 $\%$ 100.00

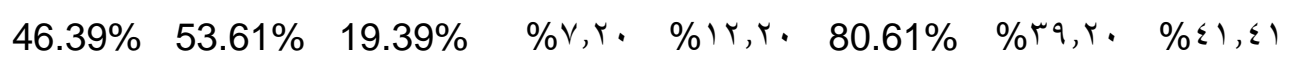

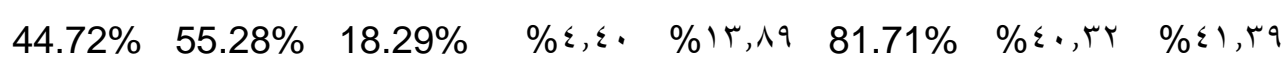

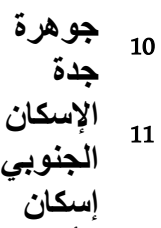

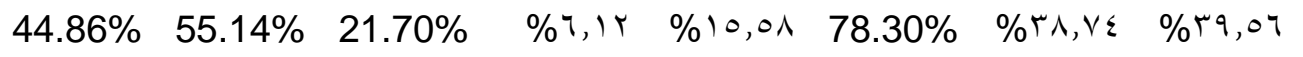
$44.48 \% \quad 55.52 \% \quad 40.99 \% \quad \% 10$, , $\quad \%$ \%

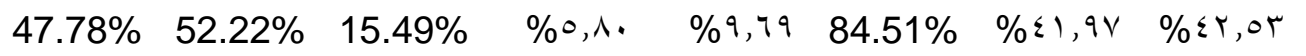
48.63\% 51.37\% $10.64 \% \quad \%$, rq $\%$ \%, ro $\quad 89.36 \%$ \% $\begin{array}{llllllll}47.07 \% & 52.93 \% & 11.78 \% & 3.33 \% & 8.45 \% & 88.22 \% & 43.74 \% & 44.49 \%\end{array}$

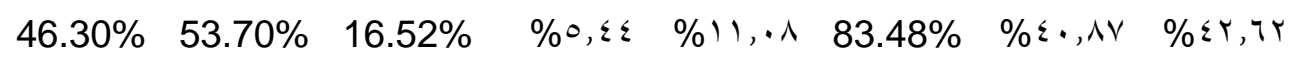

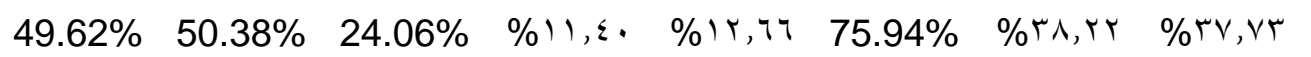
$45.63 \% \quad 54.37 \%$

$41.74 \%$ $37.75 \%$ $0.00 \% \quad 100.00$ \%

$41.53 \% \quad 58.47 \% \quad 48.8$ $45.85 \%$ $46.30 \%$

$54.15 \%$

\section{$\% 8.70 \%$}

$\%$ \%), \% 11,71

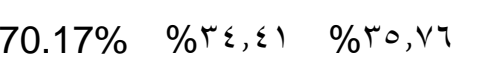

19 28 $28.53 \% \quad 71.47 \%$ 427 $42.71 \%$ $42.88 \%$ $57.29 \%$ (08.08\% \%ry,or $\% 40,00$ $41.55 \%$ \%\^,\&r \%rr,ir 20 41 $41.90 \% \quad 58.10 \% \quad 82$ $42.08 \% \quad 57.92 \% \quad 75$. $33.20 \%$ $39.23 \%$ $66.80 \%$ $\% 90$ $50.32 \%$ \%r 1 , \% \%

$54.29 \%$ $\% r \cdot, 9 q \%$ \%r,r. 21 22 $8.83 \% \% 17,01 \%$ \%r, rr $51.17 \% \quad \%$ ro, r \% \% $\%$ 23 $\%$
$60.77 \% \quad 84$
$84.74 \%$ 


\begin{tabular}{|c|c|c|c|c|c|c|c|c|c|c|}
\hline $\begin{array}{r}100.00 \\
\%\end{array}$ & $35.44 \%$ & $64.56 \%$ & $84.68 \%$ & 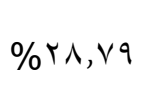 & $\% 00, \wedge 9$ & $15.32 \%$ & $\% 7,70$ & $\% \wedge, \uparrow \vee$ & الثغدية الثية & 33 \\
\hline $\begin{array}{r}100.00 \\
\%\end{array}$ & $37.72 \%$ & $62.28 \%$ & $79.26 \%$ & $\%$ \%q,. 1 & $\% 0 \cdot$, ro & $20.74 \%$ & $\% \wedge, \vee \backslash$ & $\% \backslash r, \cdot r$ & الغزبية & 34 \\
\hline $\begin{array}{r}100.00 \\
\%\end{array}$ & $40.83 \%$ & $59.17 \%$ & $66.71 \%$ & $\% r \leq, O r$ & $\% \leq r, 19$ & $33.29 \%$ & \%। & $\% \backslash 7,9 \wedge$ & جزء من الرويس & 35 \\
\hline $\begin{array}{r}00.00 \\
\%\end{array}$ & $39.39 \%$ & $60.61 \%$ & $68.83 \%$ & $\% r \varepsilon, 7 r$ & $\% \leq \varepsilon, 1 \wedge$ & $31.17 \%$ & $\% \backslash \leq, \vee \leq$ & $\% \backslash 7, \varepsilon r$ & الثرفية & 36 \\
\hline $\begin{array}{r}00.00 \\
\%\end{array}$ & $44.32 \%$ & $55.68 \%$ & $70.14 \%$ & $\% \mu, \cdot r$ & $\% r q, 11$ & $29.86 \%$ & $\% \backslash r, r q$ & $\% \backslash 7,0 \mathrm{~V}$ & الورود & 37 \\
\hline $\begin{array}{r}00.00 \\
\%\end{array}$ & $47.87 \%$ & $52.13 \%$ & $21.57 \%$ & $\% 9,0 \wedge$ & $\% 11,99$ & $78.43 \%$ & $\% r \wedge, r q$ & $\% \varepsilon \cdot, 1 \leq$ & النسيم & 38 \\
\hline $\begin{array}{r}100.00 \\
\%\end{array}$ & $33.97 \%$ & $66.03 \%$ & $59.56 \%$ & $\%) \varepsilon, O V$ & $\% \varepsilon \varepsilon, 99$ & $40.44 \%$ & $\% 19, \varepsilon$. & $\%$ Yl, $\cdot \varepsilon$ & بني مالك & 39 \\
\hline $\begin{array}{r}100.00 \\
\%\end{array}$ & $27.98 \%$ & $72.02 \%$ & $56.45 \%$ & $\% \vee, \wedge \wedge$ & $\% \leqslant \Lambda, O V$ & $43.55 \%$ & $\% r \cdot, 1$. & $\% r r, \leq 0$ & ومريخ & 40 \\
\hline $\begin{array}{r}100.00 \\
\%\end{array}$ & $41.85 \%$ & $58.15 \%$ & $24.84 \%$ & $\% \leqslant, q \pi$ & $\% 19,9 r$ & $75.16 \%$ & \% & $\%$ \% & وأم الذيق & 41 \\
\hline $\begin{array}{r}100.00 \\
\%\end{array}$ & $44.52 \%$ & $55.48 \%$ & $22.93 \%$ & $\% 4,19$ & $\% \backslash 7, \vee \leq$ & $77.07 \%$ & \% & $\% \sqcap \wedge, \vee \varepsilon$ & والأجواد & 42 \\
\hline $\begin{array}{r}100.00 \\
\%\end{array}$ & $42.75 \%$ & $57.25 \%$ & $23.36 \%$ & $\% \varepsilon, \wedge \Gamma$ & $\% \backslash \wedge, 04$ & $76.64 \%$ & $\% r v, q r$ & $\% r \wedge, \vee r$ & بريمان & 43 \\
\hline $\begin{array}{r}100.00 \\
\%\end{array}$ & $6.83 \%$ & $93.17 \%$ & $84.36 \%$ & $\% 1, r q$ & $\% \wedge \uparrow, \cdot \tau$ & $15.64 \%$ & $\% 0,0 \leq$ & $\% 1 \cdot, 1$. & شريمان & 44 \\
\hline $\begin{array}{r}100.00 \\
\%\end{array}$ & $37.46 \%$ & $62.54 \%$ & $74.44 \%$ & $\% r \vee, Y \wedge$ & $\% \leq V, 10$ & $25.56 \%$ & $\% 1 \cdot, 1 \wedge$ & $\% \backslash 0, \pi q$ & المطار & 45 \\
\hline $\begin{array}{r}100.00 \\
\%\end{array}$ & $38.74 \%$ & $61.26 \%$ & $35.32 \%$ & $\% \vee, \vee \cdot$ & $\% r v, \pi r$ & $64.68 \%$ & $\% r_{1}, .0$ & \%ז, & المروة & 46 \\
\hline $\begin{array}{r}100.00 \\
\%\end{array}$ & $45.98 \%$ & $54.02 \%$ & $34.20 \%$ & $\% \backslash \varepsilon, \cdot r$ & $\% r \cdot, 1 \wedge$ & $65.80 \%$ & $\%$ \%, , & $\% \Pi r, \wedge \varepsilon$ & الصفا & 47 \\
\hline $\begin{array}{r}100.00 \\
\%\end{array}$ & $45.55 \%$ & $54.45 \%$ & $44.17 \%$ & $\% \backslash \wedge, r \vee$ & $\%$ Y,$\Lambda$. & $55.83 \%$ & $\% \curlyvee \vee, \mid \wedge$ & $\% \curlyvee \wedge, 70$ & الرحاب & 48 \\
\hline $\begin{array}{r}100.00 \\
\%\end{array}$ & $41.28 \%$ & $58.72 \%$ & $71.23 \%$ & $\% r v, v o$ & $\% \leqslant r, \varepsilon \wedge$ & $28.77 \%$ & $\% \backslash r, 0 r$ & $\% 10, r \leq$ & مشرفة & 49 \\
\hline $\begin{array}{r}100.00 \\
\%\end{array}$ & $43.39 \%$ & $56.61 \%$ & $55.45 \%$ & $\%$ Y I, ^० & $\% r r, \pi)$ & $44.55 \%$ & $\% r_{1}, 0 \leq$ & $\% r r, \ldots$ & الحمر & 50 \\
\hline $\begin{array}{r}100.00 \\
\%\end{array}$ & $47.28 \%$ & $52.72 \%$ & $37.58 \%$ & $\% \backslash \wedge, \circ \vee$ & $\% 19, \cdot 1$ & $62.42 \%$ & $\% \curlyvee \wedge, \vee \backslash$ & $\% r r, v)$ & الأندلس & 51 \\
\hline $\begin{array}{r}100.00 \\
\%\end{array}$ & $38.53 \%$ & $61.47 \%$ & $72.98 \%$ & $\%$ ro, 99 & $\% \leq 7,9 \wedge$ & $27.02 \%$ & $\%$ Ir,or & $\% 1 \leq, \leq 9$ & العزيزية & 52 \\
\hline $\begin{array}{r}100.00 \\
\%\end{array}$ & $41.42 \%$ & $58.58 \%$ & $58.97 \%$ & $\%$ \% , qr & $\% r v, \cdot r$ & $41.03 \%$ & $\% \backslash 9, \leqslant 9$ & $\%$ \% 1,00 & الفيصلية & 53 \\
\hline $\begin{array}{r}100.00 \\
\%\end{array}$ & $44.34 \%$ & $55.66 \%$ & $53.83 \%$ & $\%$ \% , גт & $\%$ & $46.17 \%$ & $\% r r, \varepsilon \wedge$ & $\%$ \% & الروضة & 54 \\
\hline $\begin{array}{r}100.00 \\
\%\end{array}$ & $52.01 \%$ & $47.99 \%$ & $72.94 \%$ & $\% \leftrightarrow q, \cdot \wedge$ & $\%$ & $27.06 \%$ & $\%$ & $\% \backslash \leq, 1 T$ & الخالاية & 55 \\
\hline $\begin{array}{r}100.00 \\
\%\end{array}$ & 42.0 & $57.99 \%$ & $45.41 \%$ & $\% \backslash\{, 7 \mid$ & $\% \Gamma \cdot, \Lambda$. & $54.59 \%$ & $\% r v, \Sigma$. & $\% r v, 19$ & الثاطئ & 56 \\
\hline
\end{tabular}




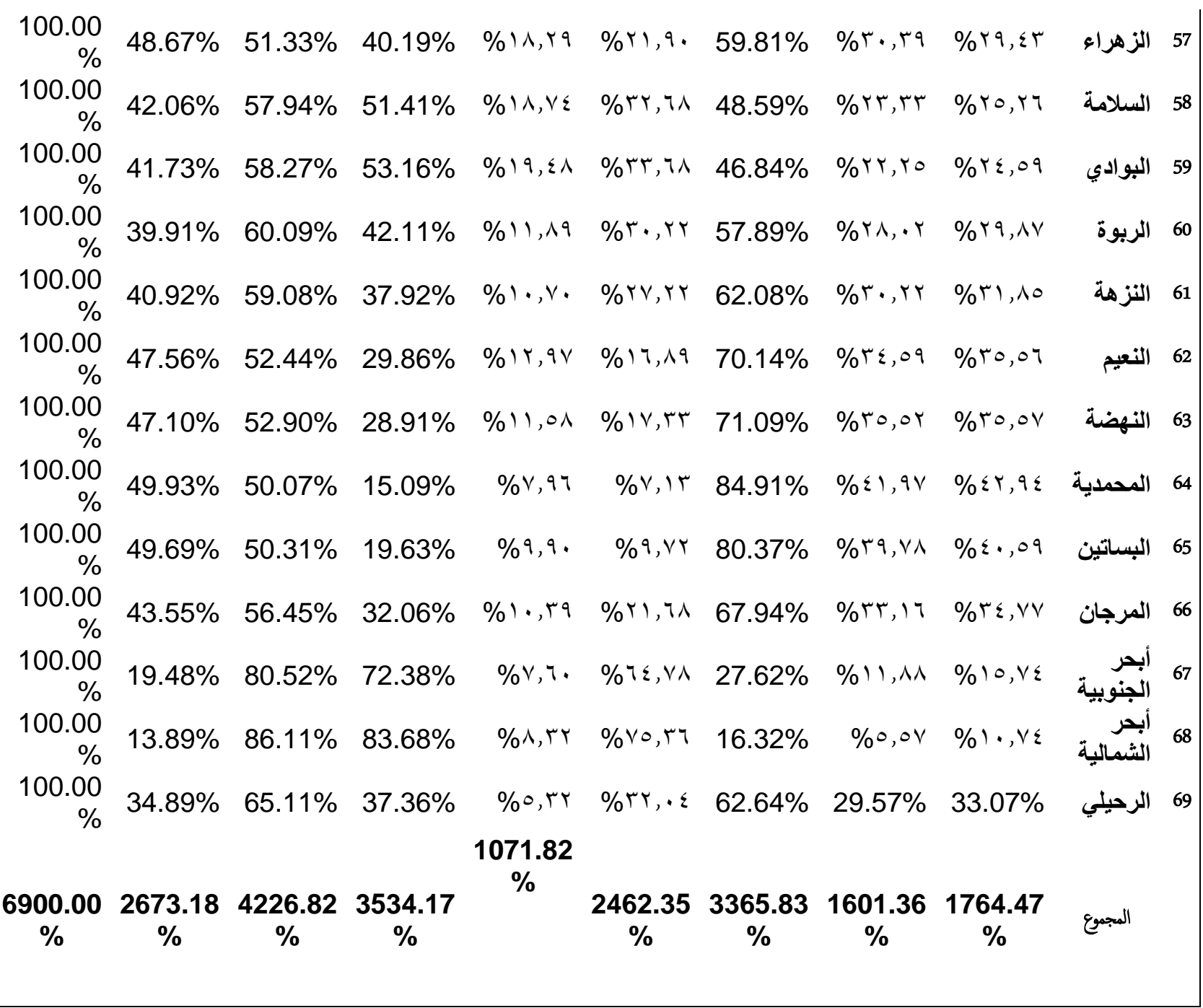

وقد بين الرسم البياني المنبثق عن الجدول r -وهو رسم بياني مصفوفي وبذات الطربقة- صورةً أكثر توازنا بما أن مجموع كل حي من حيث أثره البصري متساوٍ بتمثيل كل الميزات مجموعا ثابتا وهو . . (\% (الشكل r I). 


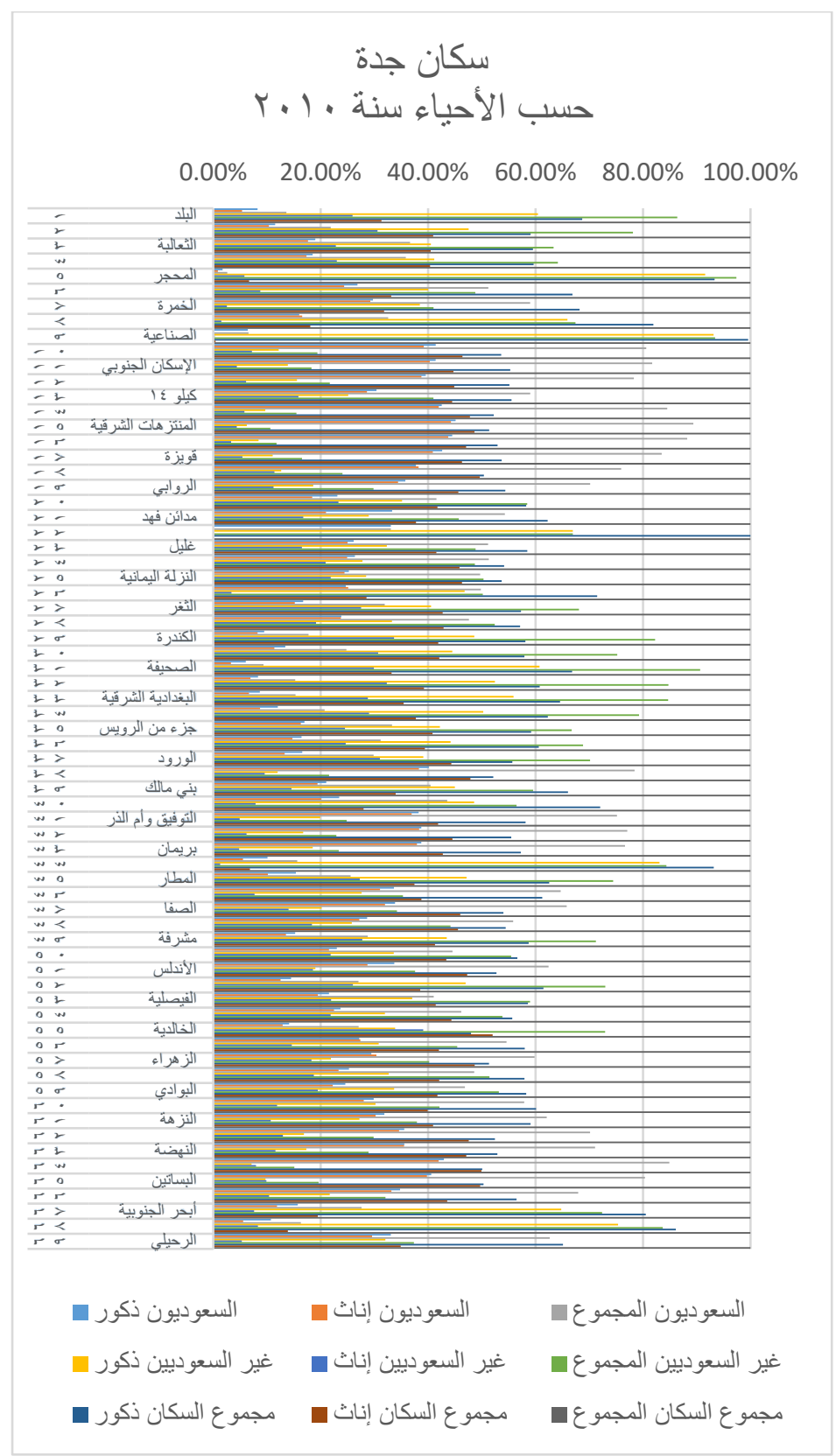

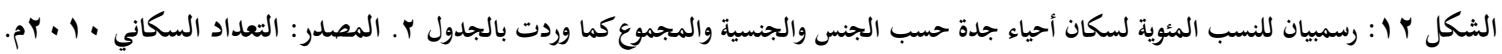

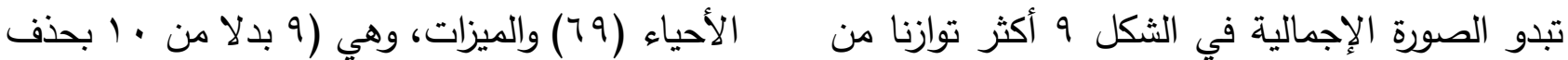

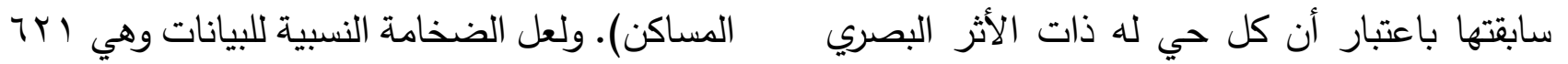

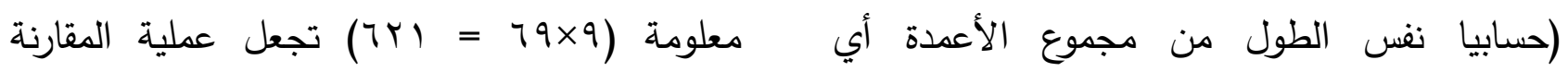

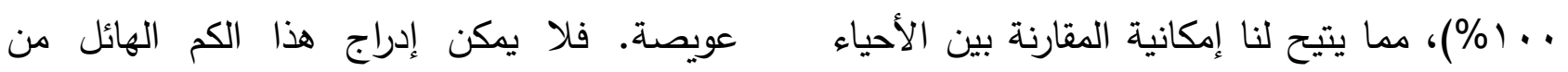
مع الأخذ بعين الاعتبار عدد مفردات البيانات أي المعلومات في صفحة كتاب دون الإخلال بالمقروئية 
والوضوح. لذلك، وبعد تسوية الأسطر (أي المفردات تقع إعادة ترتيب محتوى الجدول بحيث يصبح مجموع

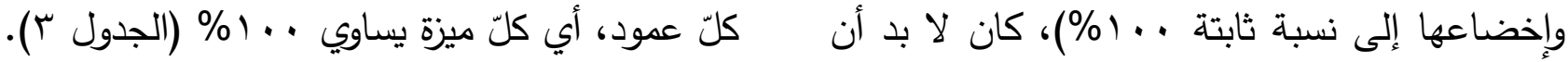

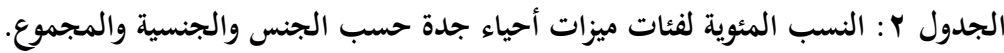

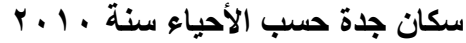

\begin{tabular}{|c|c|c|c|c|c|c|c|c|c|c|}
\hline \multicolumn{3}{|c|}{ مجموع السكان } & \multicolumn{3}{|c|}{ غير السعوديين } & \multicolumn{3}{|c|}{ السعوديون } & \multirow[b]{2}{*}{ | ل الحي } & \multirow[b]{2}{*}{ قم } \\
\hline المجموع & إناث & ذكور & المجموع & إناث & ذكور & المجموع & | إثاث & ذكور & & \\
\hline $1.73 \%$ & $1.30 \%$ & $2.05 \%$ & $3.08 \%$ & $2.62 \%$ & $3.32 \%$ & $0.46 \%$ & $0.38 \%$ & $0.54 \%$ & البلا & 1 \\
\hline $1.69 \%$ & $1.65 \%$ & $1.71 \%$ & $2.70 \%$ & $3.00 \%$ & $2.54 \%$ & $0.72 \%$ & $0.71 \%$ & $0.73 \%$ & & 2 \\
\hline $0.78 \%$ & $0.76 \%$ & $0.80 \%$ & $1.02 \%$ & $1.04 \%$ & $1.00 \%$ & $0.56 \%$ & $0.56 \%$ & $0.56 \%$ & & 3 \\
\hline $1.41 \%$ & $1.36 \%$ & $1.44 \%$ & $1.86 \%$ & $1.89 \%$ & $1.84 \%$ & $0.99 \%$ & $0.99 \%$ & $0.98 \%$ & بترو & 4 \\
\hline $0.43 \%$ & $0.07 \%$ & $0.69 \%$ & $0.87 \%$ & $0.15 \%$ & $1.26 \%$ & $0.02 \%$ & $0.02 \%$ & $0.03 \%$ & & 5 \\
\hline $0.63 \%$ & $0.50 \%$ & $0.72 \%$ & $0.63 \%$ & $0.32 \%$ & $0.79 \%$ & $0.62 \%$ & $0.62 \%$ & $0.63 \%$ & الميناء & 6 \\
\hline $0.42 \%$ & $0.32 \%$ & $0.49 \%$ & $0.35 \%$ & $0.06 \%$ & $0.51 \%$ & $0.48 \%$ & $0.50 \%$ & $0.47 \%$ & ال ال & 7 \\
\hline $0.11 \%$ & $0.05 \%$ & $0.16 \%$ & $0.15 \%$ & $0.01 \%$ & $0.23 \%$ & $0.07 \%$ & $0.07 \%$ & $0.07 \%$ & المس & 8 \\
\hline $0.03 \%$ & $0.00 \%$ & $0.04 \%$ & $0.05 \%$ & $0.00 \%$ & $0.08 \%$ & $0.00 \%$ & $0.00 \%$ & $0.01 \%$ & & 9 \\
\hline $0.19 \%$ & $0.21 \%$ & $0.18 \%$ & $0.08 \%$ & $0.08 \%$ & $0.07 \%$ & $0.30 \%$ & $0.31 \%$ & $0.30 \%$ & جوهر & 10 \\
\hline $1.45 \%$ & $1.55 \%$ & $1.38 \%$ & $0.55 \%$ & $0.37 \%$ & $0.64 \%$ & $2.31 \%$ & $2.38 \%$ & $2.25 \%$ & ن الجنوبي & 11 \\
\hline $2.34 \%$ & $2.51 \%$ & $2.21 \%$ & $1.04 \%$ & $0.83 \%$ & $1.15 \%$ & $3.57 \%$ & $3.67 \%$ & $3.47 \%$ & لأمير فواز & 12 \\
\hline $2.63 \%$ & $2.80 \%$ & $2.51 \%$ & $2.21 \%$ & $2.43 \%$ & $2.09 \%$ & $3.03 \%$ & $3.06 \%$ & $3.00 \%$ & كيلو \& 1 & 13 \\
\hline $0.95 \%$ & $1.09 \%$ & $0.86 \%$ & $0.30 \%$ & $0.32 \%$ & $0.29 \%$ & $1.57 \%$ & $1.63 \%$ & $1.52 \%$ & كيلو 11 & 14 \\
\hline $0.65 \%$ & $0.76 \%$ & $0.58 \%$ & $0.14 \%$ & $0.17 \%$ & $0.13 \%$ & $1.14 \%$ & $1.18 \%$ & $1.11 \%$ & المنتزهات الشرقية & 15 \\
\hline $1.13 \%$ & $1.27 \%$ & $1.03 \%$ & $0.27 \%$ & $0.22 \%$ & $0.30 \%$ & $1.94 \%$ & $2.01 \%$ & $1.89 \%$ & المتززهات الشرقية r & 16 \\
\hline $2.25 \%$ & $2.49 \%$ & $2.08 \%$ & $0.76 \%$ & $0.71 \%$ & $0.79 \%$ & $3.66 \%$ & $3.73 \%$ & $3.60 \%$ & & 17 \\
\hline $1.00 \%$ & $1.18 \%$ & $0.86 \%$ & $0.49 \%$ & $0.66 \%$ & $0.40 \%$ & $1.48 \%$ & $1.55 \%$ & $1.41 \%$ & & 18 \\
\hline $2.97 \%$ & $3.25 \%$ & $2.78 \%$ & $1.82 \%$ & $1.95 \%$ & $1.75 \%$ & $4.07 \%$ & $4.15 \%$ & $3.99 \%$ & & 19 \\
\hline $4.77 \%$ & $4.76 \%$ & $4.77 \%$ & $5.72 \%$ & $6.47 \%$ & $5.31 \%$ & $3.86 \%$ & $3.57 \%$ & $4.13 \%$ & & 20 \\
\hline $3.24 \%$ & $2.93 \%$ & $3.47 \%$ & $3.04 \%$ & $3.17 \%$ & $2.98 \%$ & $3.43 \%$ & $2.77 \%$ & $4.05 \%$ & & 21 \\
\hline $0.00 \%$ & $0.00 \%$ & $0.01 \%$ & $0.01 \%$ & $0.00 \%$ & $0.01 \%$ & $0.00 \%$ & $0.00 \%$ & $0.01 \%$ & & 22 \\
\hline $2.34 \%$ & $2.33 \%$ & $2.35 \%$ & $2.35 \%$ & $2.26 \%$ & $2.40 \%$ & $2.34 \%$ & $2.38 \%$ & $2.30 \%$ & غل & 23 \\
\hline $0.54 \%$ & $0.59 \%$ & $0.50 \%$ & $0.54 \%$ & $0.66 \%$ & $0.47 \%$ & $0.54 \%$ & $0.54 \%$ & $0.53 \%$ & القريات & 24 \\
\hline $2.03 \%$ & $2.25 \%$ & $1.87 \%$ & $2.10 \%$ & $2.59 \%$ & $1.83 \%$ & $1.97 \%$ & $2.01 \%$ & $1.92 \%$ & & 25 \\
\hline $0.61 \%$ & $0.42 \%$ & $0.75 \%$ & $0.63 \%$ & $0.12 \%$ & $0.91 \%$ & $0.60 \%$ & $0.63 \%$ & $0.57 \%$ & النز النز & 26 \\
\hline $1.48 \%$ & $1.51 \%$ & $1.45 \%$ & $2.06 \%$ & $2.37 \%$ & $1.90 \%$ & $0.92 \%$ & $0.91 \%$ & $0.93 \%$ & الثة & 27 \\
\hline $1.15 \%$ & $1.18 \%$ & $1.13 \%$ & $1.24 \%$ & $1.29 \%$ & $1.22 \%$ & $1.07 \%$ & $1.11 \%$ & $1.03 \%$ & الفب. & 28 \\
\hline $1.57 \%$ & $1.57 \%$ & $1.56 \%$ & $2.65 \%$ & $3.07 \%$ & $2.41 \%$ & $0.54 \%$ & $0.53 \%$ & $0.56 \%$ & الكندرة & 29 \\
\hline $0.93 \%$ & $0.94 \%$ & $0.93 \%$ & $1.44 \%$ & $1.67 \%$ & $1.32 \%$ & $0.45 \%$ & $0.43 \%$ & $0.47 \%$ & السبيل & 30 \\
\hline $0.69 \%$ & $0.55 \%$ & $0.79 \%$ & $1.28 \%$ & $1.20 \%$ & $1.32 \%$ & $0.13 \%$ & $0.09 \%$ & $0.16 \%$ & الصحيفة & 31 \\
\hline $0.50 \%$ & $0.47 \%$ & $0.53 \%$ & $0.88 \%$ & $0.95 \%$ & $0.84 \%$ & $0.15 \%$ & $0.14 \%$ & $0.16 \%$ & العما - ال العـا & 32 \\
\hline $0.84 \%$ & $0.71 \%$ & $0.93 \%$ & $1.46 \%$ & $1.41 \%$ & $1.49 \%$ & $0.25 \%$ & $0.23 \%$ & $0.27 \%$ & البغدادية الشرقية & 33 \\
\hline $0.43 \%$ & $0.39 \%$ & $0.46 \%$ & $0.71 \%$ & $0.73 \%$ & $0.69 \%$ & $0.18 \%$ & $0.15 \%$ & $0.20 \%$ & البغدادية الغربية & 34 \\
\hline $1.77 \%$ & $1.73 \%$ & $1.80 \%$ & $2.42 \%$ & $2.53 \%$ & $2.37 \%$ & $1.15 \%$ & $1.17 \%$ & $1.13 \%$ & جزء من الرويس & 35 \\
\hline $2.04 \%$ & $1.92 \%$ & $2.12 \%$ & $2.88 \%$ & $2.93 \%$ & $2.85 \%$ & $1.24 \%$ & $1.22 \%$ & $1.26 \%$ & & 36 \\
\hline $0.22 \%$ & $0.23 \%$ & $0.21 \%$ & $0.31 \%$ & $0.39 \%$ & $0.27 \%$ & $0.13 \%$ & $0.12 \%$ & $0.13 \%$ & الورود & 37 \\
\hline $1.08 \%$ & $1.24 \%$ & $0.97 \%$ & $0.48 \%$ & $0.60 \%$ & $0.41 \%$ & $1.66 \%$ & $1.69 \%$ & $1.63 \%$ & & 38 \\
\hline $2.48 \%$ & $2.02 \%$ & $2.82 \%$ & $3.03 \%$ & $2.11 \%$ & $3.54 \%$ & $1.96 \%$ & $1.96 \%$ & $1.96 \%$ & بذ & 39 \\
\hline
\end{tabular}




\begin{tabular}{|c|c|c|c|c|c|c|c|c|c|c|}
\hline $0.65 \%$ & $0.43 \%$ & $0.80 \%$ & $0.75 \%$ & $0.30 \%$ & $1.00 \%$ & $0.55 \%$ & $0.53 \%$ & $0.57 \%$ & ومريخ & 40 \\
\hline $0.71 \%$ & $0.71 \%$ & $0.71 \%$ & $0.36 \%$ & $0.20 \%$ & $0.45 \%$ & $1.04 \%$ & $1.07 \%$ & $1.02 \%$ & وأم الذر & 41 \\
\hline $2.03 \%$ & $2.16 \%$ & $1.93 \%$ & $0.95 \%$ & $0.73 \%$ & $1.08 \%$ & $3.05 \%$ & $3.16 \%$ & $2.95 \%$ & والأجواد & 42 \\
\hline $0.90 \%$ & $0.92 \%$ & $0.88 \%$ & $0.43 \%$ & $0.25 \%$ & $0.53 \%$ & $1.34 \%$ & $1.38 \%$ & $1.30 \%$ & & 43 \\
\hline $0.21 \%$ & $0.03 \%$ & $0.34 \%$ & $0.37 \%$ & $0.02 \%$ & $0.56 \%$ & $0.06 \%$ & $0.05 \%$ & $0.08 \%$ & ن & 44 \\
\hline $0.75 \%$ & $0.67 \%$ & $0.81 \%$ & $1.15 \%$ & $1.19 \%$ & $1.12 \%$ & $0.37 \%$ & $0.31 \%$ & $0.43 \%$ & & 45 \\
\hline $1.96 \%$ & $1.82 \%$ & $2.07 \%$ & $1.42 \%$ & $0.88 \%$ & $1.72 \%$ & $2.48 \%$ & $2.48 \%$ & $2.48 \%$ & & 46 \\
\hline $6.70 \%$ & $7.37 \%$ & $6.21 \%$ & $4.70 \%$ & $5.47 \%$ & $4.28 \%$ & $8.59 \%$ & $8.70 \%$ & $8.50 \%$ & & 47 \\
\hline $1.46 \%$ & $1.60 \%$ & $1.37 \%$ & $1.33 \%$ & $1.57 \%$ & $1.20 \%$ & $1.59 \%$ & $1.62 \%$ & $1.57 \%$ & & 48 \\
\hline $3.37 \%$ & $3.33 \%$ & $3.40 \%$ & $4.93 \%$ & $5.45 \%$ & $4.65 \%$ & $1.89 \%$ & $1.85 \%$ & $1.93 \%$ & & 49 \\
\hline $0.78 \%$ & $0.81 \%$ & $0.75 \%$ & $0.88 \%$ & $0.99 \%$ & $0.83 \%$ & $0.67 \%$ & $0.68 \%$ & $0.67 \%$ & & 50 \\
\hline $0.58 \%$ & $0.65 \%$ & $0.52 \%$ & $0.44 \%$ & $0.62 \%$ & $0.35 \%$ & $0.70 \%$ & $0.67 \%$ & $0.73 \%$ & & 51 \\
\hline $4.09 \%$ & $3.77 \%$ & $4.31 \%$ & $6.12 \%$ & $6.19 \%$ & $6.08 \%$ & $2.15 \%$ & $2.08 \%$ & $2.22 \%$ & & 52 \\
\hline $3.13 \%$ & $3.10 \%$ & $3.15 \%$ & $3.79 \%$ & $4.00 \%$ & $3.67 \%$ & $2.50 \%$ & $2.48 \%$ & $2.53 \%$ & & 53 \\
\hline $1.81 \%$ & $1.92 \%$ & $1.73 \%$ & $2.00 \%$ & $2.30 \%$ & $1.83 \%$ & $1.63 \%$ & $1.65 \%$ & $1.61 \%$ & & 54 \\
\hline $0.51 \%$ & $0.64 \%$ & $0.42 \%$ & $0.77 \%$ & $1.17 \%$ & $0.55 \%$ & $0.27 \%$ & $0.27 \%$ & $0.27 \%$ & & 55 \\
\hline $1.01 \%$ & $1.02 \%$ & $1.01 \%$ & $0.94 \%$ & $0.86 \%$ & $0.99 \%$ & $1.08 \%$ & $1.13 \%$ & $1.03 \%$ & & 56 \\
\hline $1.34 \%$ & $1.56 \%$ & $1.18 \%$ & $1.10 \%$ & $1.42 \%$ & $0.93 \%$ & $1.56 \%$ & $1.65 \%$ & $1.47 \%$ & & 57 \\
\hline $2.48 \%$ & $2.49 \%$ & $2.47 \%$ & $2.61 \%$ & $2.70 \%$ & $2.57 \%$ & $2.35 \%$ & $2.35 \%$ & $2.35 \%$ & الس & 58 \\
\hline $2.62 \%$ & $2.62 \%$ & $2.62 \%$ & $2.86 \%$ & $2.97 \%$ & $2.80 \%$ & $2.39 \%$ & $2.37 \%$ & $2.42 \%$ & & 59 \\
\hline $4.69 \%$ & $4.48 \%$ & $4.84 \%$ & $4.06 \%$ & $3.25 \%$ & $4.49 \%$ & $5.30 \%$ & $5.34 \%$ & $5.26 \%$ & & 60 \\
\hline $2.70 \%$ & $2.65 \%$ & $2.74 \%$ & $2.10 \%$ & $1.69 \%$ & $2.33 \%$ & $3.27 \%$ & $3.32 \%$ & $3.23 \%$ & & 61 \\
\hline $1.00 \%$ & $1.14 \%$ & $0.90 \%$ & $0.61 \%$ & $0.76 \%$ & $0.54 \%$ & $1.37 \%$ & $1.41 \%$ & $1.34 \%$ & & 62 \\
\hline $1.01 \%$ & $1.14 \%$ & $0.92 \%$ & $0.60 \%$ & $0.68 \%$ & $0.56 \%$ & $1.40 \%$ & $1.46 \%$ & $1.35 \%$ & & 63 \\
\hline $0.96 \%$ & $1.14 \%$ & $0.82 \%$ & $0.30 \%$ & $0.44 \%$ & $0.22 \%$ & $1.58 \%$ & $1.63 \%$ & $1.54 \%$ & & 64 \\
\hline $0.34 \%$ & $0.40 \%$ & $0.29 \%$ & $0.14 \%$ & $0.19 \%$ & $0.10 \%$ & $0.53 \%$ & $0.54 \%$ & $0.51 \%$ & & 65 \\
\hline $0.33 \%$ & $0.35 \%$ & $0.32 \%$ & $0.22 \%$ & $0.20 \%$ & $0.23 \%$ & $0.44 \%$ & $0.45 \%$ & $0.44 \%$ & & 66 \\
\hline $0.09 \%$ & $0.04 \%$ & $0.12 \%$ & $0.13 \%$ & $0.04 \%$ & $0.18 \%$ & $0.05 \%$ & $0.04 \%$ & $0.05 \%$ & & 67 \\
\hline $0.13 \%$ & $0.04 \%$ & $0.20 \%$ & $0.23 \%$ & $0.06 \%$ & $0.32 \%$ & $0.04 \%$ & $0.03 \%$ & $0.05 \%$ & شأ & 68 \\
\hline $0.14 \%$ & $0.12 \%$ & $0.16 \%$ & $0.11 \%$ & $0.04 \%$ & $0.14 \%$ & $0.17 \%$ & $0.17 \%$ & $0.18 \%$ & & 69 \\
\hline $100.00 \%$ & $100.00 \%$ & $100.00 \%$ & $0.00 \%$ & $00.00 \%$ & $.00 .00 \%$ & $00.00 \%$ & $100.00 \%$ & $100.00 \%$ & & \\
\hline
\end{tabular}

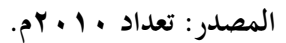

ترتيب الأحياء حسب النسبة المئوية للذكور غير السعوديين لأننا نعتبر هذه الميزة الأكثر تأثيرا على الصى تصنيف الأحياء (الشكل باء لنئر).
بالإضافة، إن عدم ترتيب الأحياء وإدراجها دون ترتيب، أي بصفة عشوائية بالرسم البياني، يزيد في تعميق مشكل عمليات التحليل والاستنتاج والمقارنة بين الميزات عن كل حي، حيث إن المرور من حي مي لله ميزات مختلفة عن الحي السابق وعن الحي الموالي

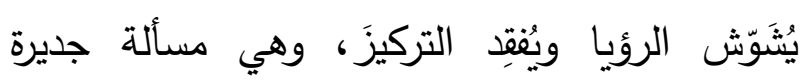

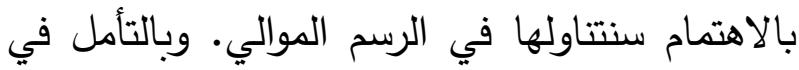

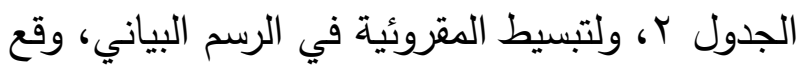




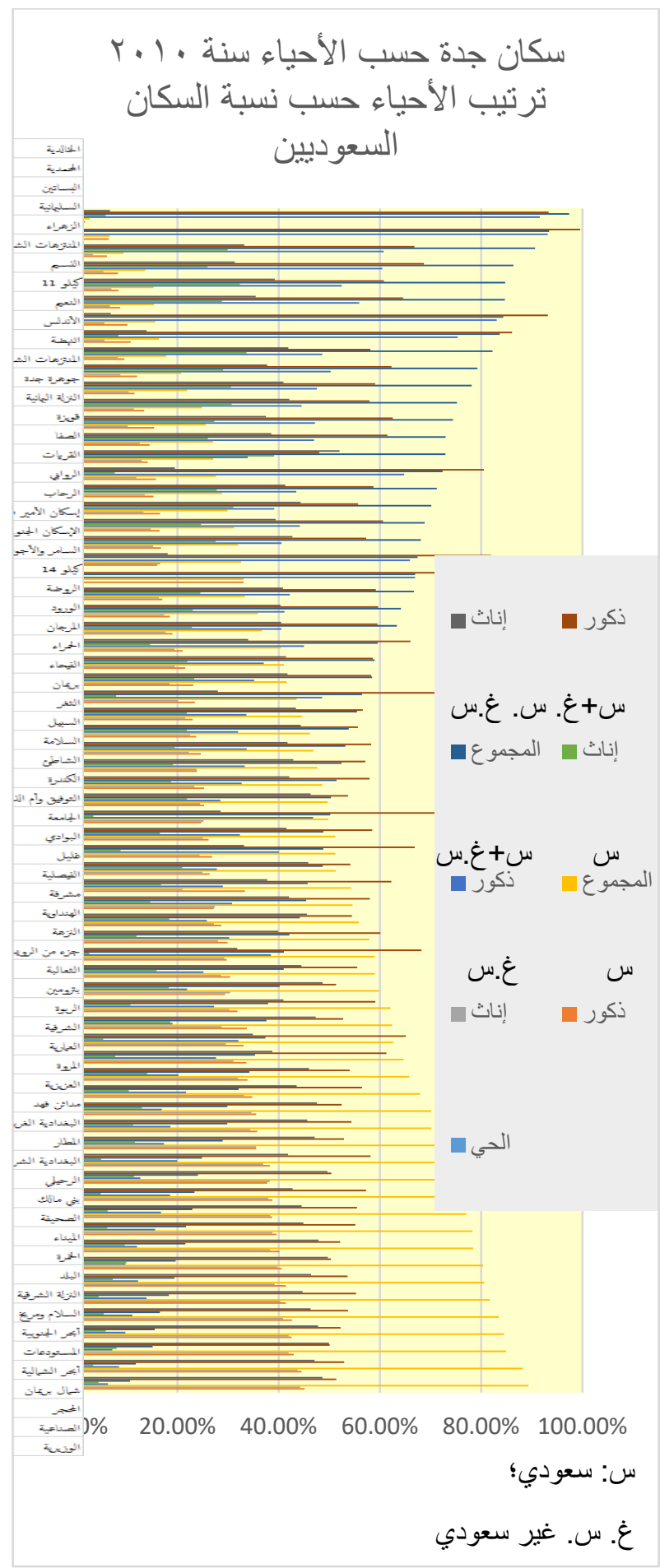


الشكل ب ا : رسمبيان للنسب المئوية لسكان أحياء جدة حسب وزن كل ميزة من الميزات ال 9 عن الجنس والجنسية والمجموع، كما وردت

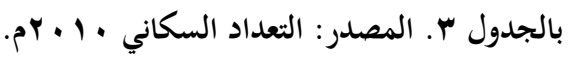

Matrice ordonnable Orderable) التراتبية (matrix

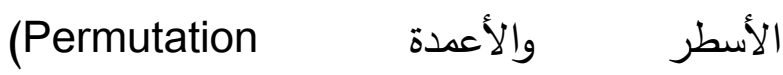
Permutation)

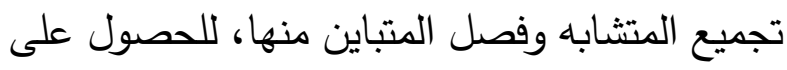

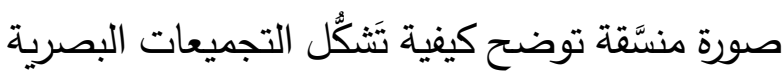
للأسطر (الأحياء) والميزات (الجنس والجنسية). وعليه يمكن استخدام نتائج ترتيب المصفوفة إلى تجميعات ذات دلالة وجديرة بالتحليل. بقي أن نقول إنه في حالة وجود مُكوِّن طويل نسبيا

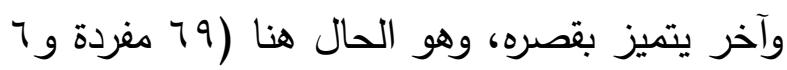
ميزات)، يمكن تعويض المصفوفة الترتيبية بما أطلقَ لئق

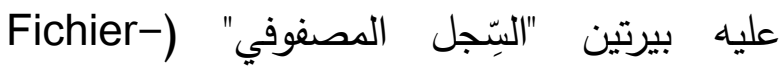
matrice Matrix-file رسمبياني تقوم على ذات مبدإ المناقلة، إلا أنه لتيسير العملية، عادة ما يقع الترتيب المسبق لواحدة من لون

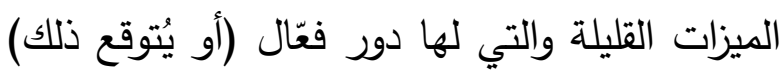
في تصنيف الميزات الأخرى من حيث التقابل والتماثل. وهذا ما تم في الحالة الراهنة، حيث وقع ترتيب مختلف المفردات من خلال موقعها في ترتيب ميزة الذكور غير السعوديين باعتبارهم من العمالة الأجنبية، بما يتبع ذاك من تمركزهم غالبا في أحياء

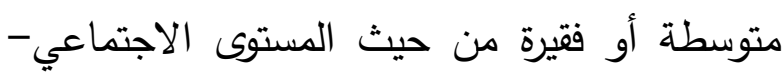
الاقتصادي. ثم تُرتَب الميزات من حيث تشئ تشابهها، أو الو
لعلَّ أول ملحوظة يمكن استتتاجها من الرسمبيان هي أن ترتيب الأحياء حسب ميزة "السكان غير السعوديين

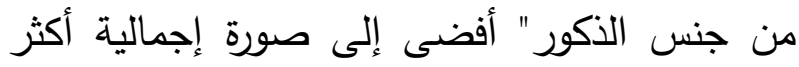
توازنا وتقابلا، باعتبار أن نسبة الذكور غير السعوديين هي تقريبا متعاكسة مع نسبة الإناث غير السعوديات.

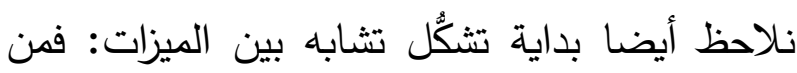
جهة، تتشكل الميزات التصاعدية من حي الخالدية (الأقل من حيث وزنِ نسبة الذكور غير السعوديين نسبةً إلى عدد سكانه الإجمالي من مجموع سكان جدة)، إلى حي الوزيرية الذي يتكون سكَّانُه قليلو العدد الإنهاع

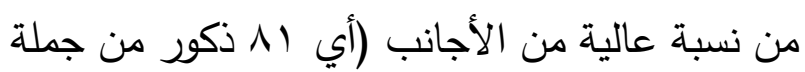
اب ا ذكور) من الذكور غير السعوديين باعتباره حيا

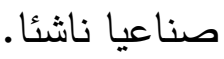
؛ ,ه . الرسم حسب التحليل الرسمبياني للمعلومات في حالة تواجد محورين ذوي مُكِّنات كل منهما قابلةً للترتيب، أي أنه بالإمكان استبدال الرتبة التي ترد

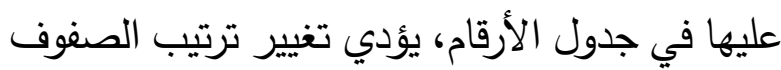
والأعمدة على حد سواء إلى تقريب المجموعات بعضها من بعض بالرجوع إلى النظام الرسمبياني

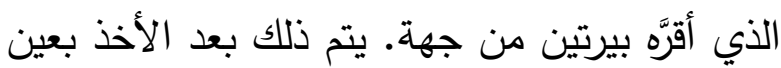

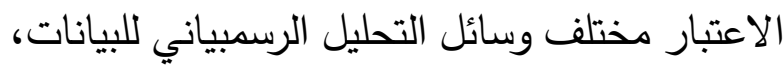
والعدد المرتفع لهذه البيانات، والتأكد من كون الميزات والمفردات قابلة للترتيب على حد سواء ـ وهذه الجوانب تكرس المبدأ الذي تقوم عليه المصفوفة (الرسمبيانية) 
تقابلها، أو اختلافها مع الميزة التي اتُّذت كقاعدة الأكثر "سَعْودة"وتأصلا، إلى الأحياء التي تهيمن فيها نسب عالية من غير السعوديين، وخاصة منهم للترتيب.

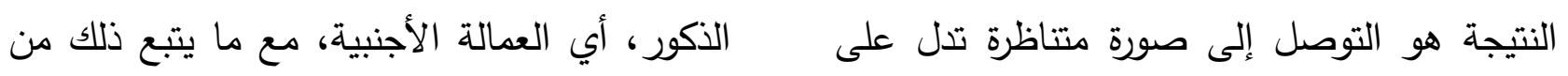

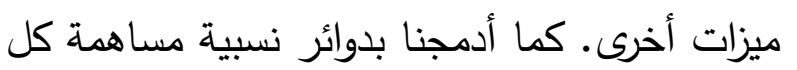
تركيبة اجتماعية ومكانية جد متباينة في جدة، وهي

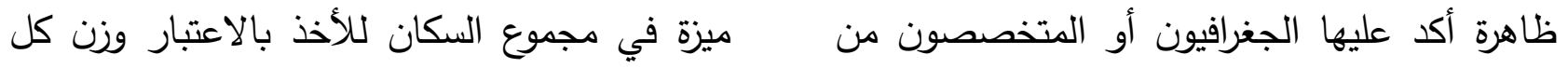

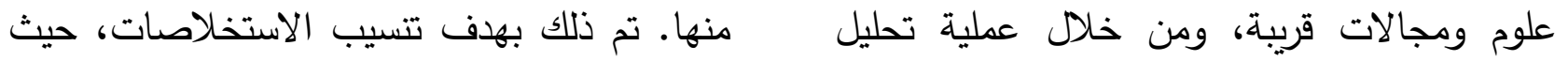
تأتي نسبة الذكور من سعوديين وغير سعوديين من المجموع في المقام الأول، تليها نسبة مجموع الإناث

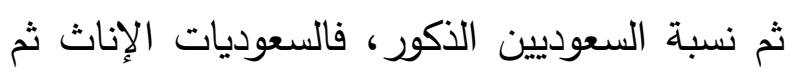
الذكور غير السعوديين فالإناث غير السعوديات

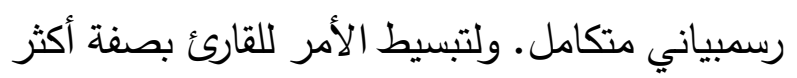

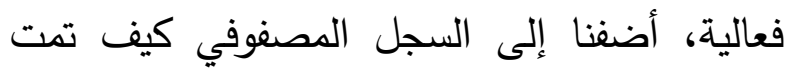

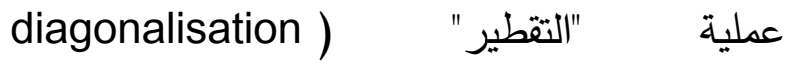
ذات diagonalisation )، بمعنى الترتيب حسب المقطرة

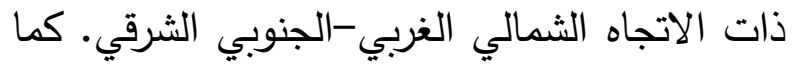

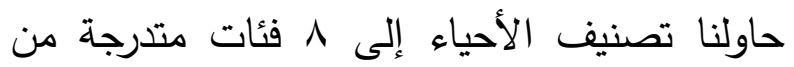

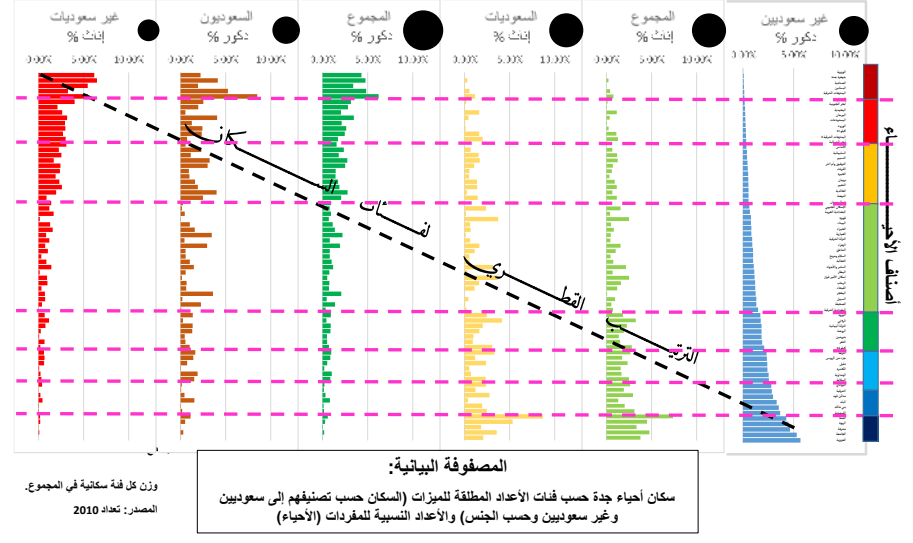

الشكل § ا : المصفوفة الترتيبية المبينة لخصائص أحياء جدة من حيث الجنس والجنسية.

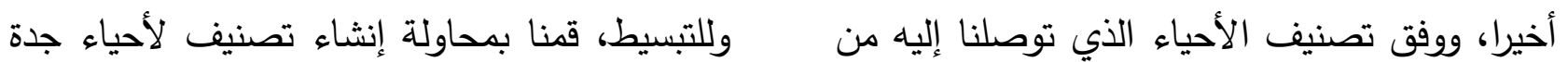

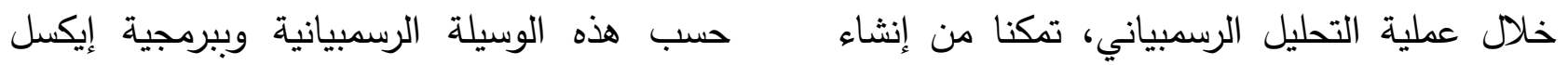
مفتاح متدرج من ^ خانات استخدمناها في إنتاج خريطة تصنيفية لأحياء جدة طبقا للبيانات الأولية حول السكان، ووضعنا لها مفتاحا تأليفيا توليفيا. 


$$
\begin{aligned}
& \text { وبطريقة شبه آلية حيث هي لا تسمح بإنشائها بطريقة } \\
& \text { آلية` لكن يمكن تطويرها مستقبلا (الثكل } 0 \text { 1). }
\end{aligned}
$$

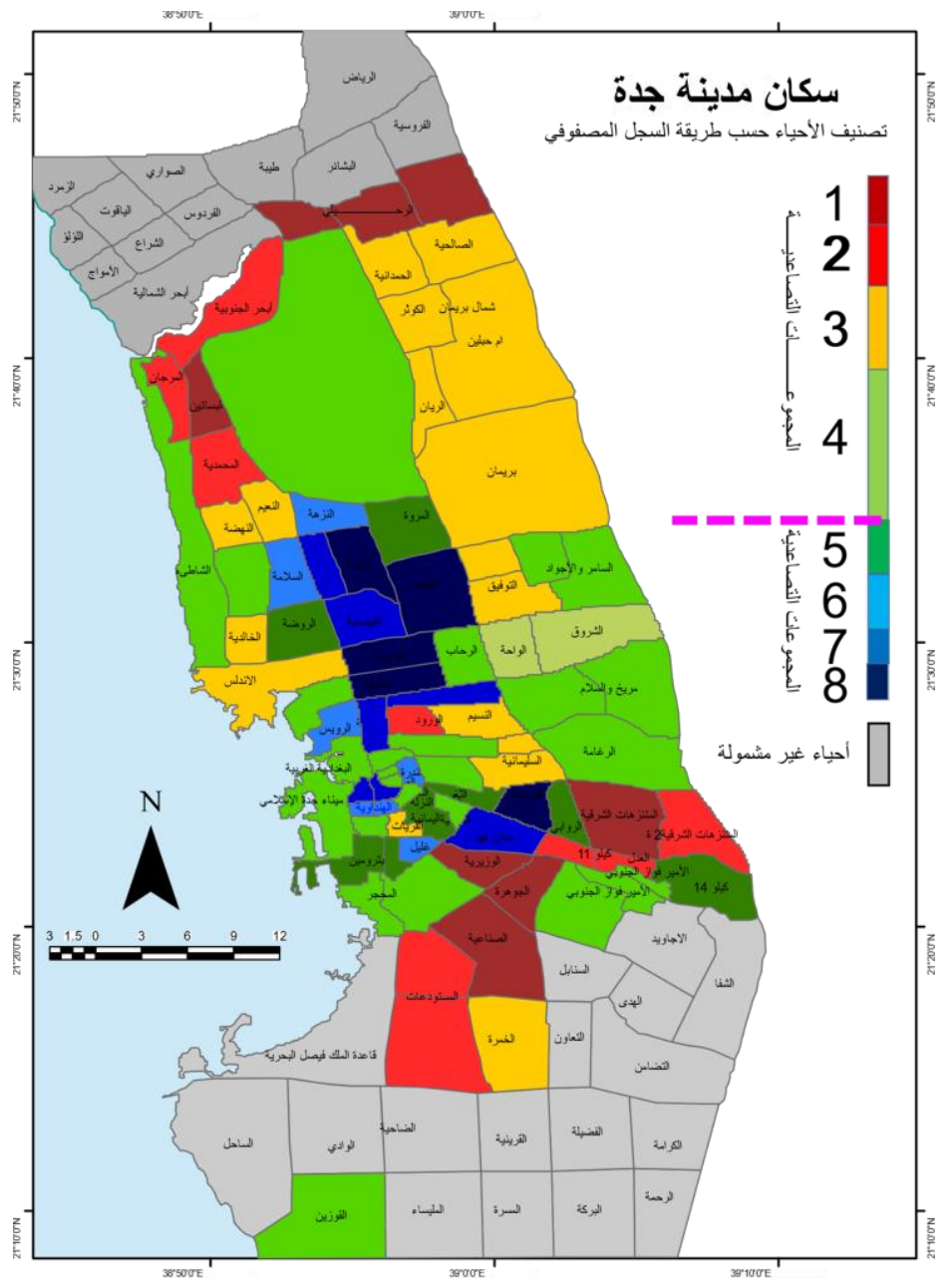

الشكل ه 1 : خريطة أحياء جدة مصنفة بطريقة السجل المصفوفي الخاضع لمبدإ المصفوفة الترتيبية.

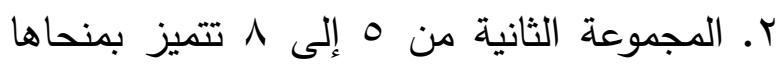
التتازلي حسب ترتيب الميزات الذي توصلنا إليه.

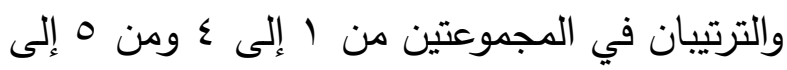
^ متصلان. والتجاور بين الأرقام له دلالة مؤكدة، إلى ودن إلى
وقد صنفت الأحياء إلى مجموعتين أساسيتين مندرجة عن التحليل المصفوفي:

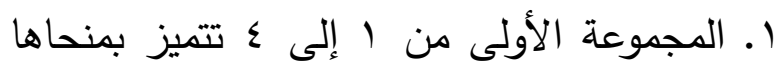
التصاعدي حسب ترتيب الميزات الذي توصلنا إليه.

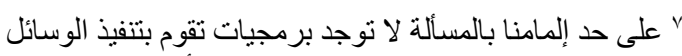

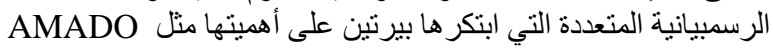
المفتوحة و Cartes et Données. 
فرضيتا الأولى من خلال مثال طُبِّق على سكان أحياء مدينة جدة حسب ميزات الجنس والجنسية قامت من هات على تشكيل صورة رسمبيانية معبرة عن طريق تقنية السجل المصفوفي الترتيبي الذي أدى إلى تصنيف أحياء جدة وفق إعادة ترتيب الميزات، وهو تصنيف الفي الفي لصني قابل للتطوير ومزيد التحسين.

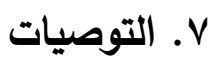

نجم عن هذا البحث إقرار عدة استخلاصات وتوصيات من خلال مقاربة علامية-سيميولوجية للرسوم البيانية تهدف إلى إيصال الرسائل البيانية

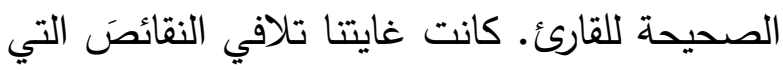
تتسم بها الكثير من الرسوم البيانية المستخدمة اليوم

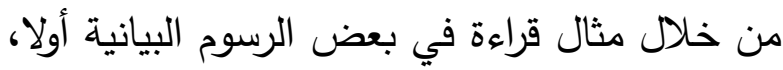
ومن خلال تطبيق أولي على أحياء جدة نرجو تطويره

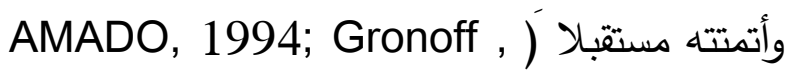

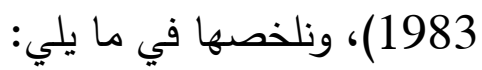
ضرورة توفير المقروئية الجيدة للرسمبيانات؛ تلافي بعض الرسوم البيانية المألوفة كالقطاعات

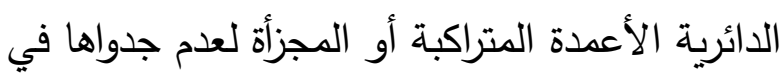

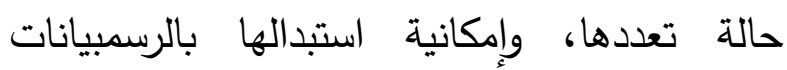

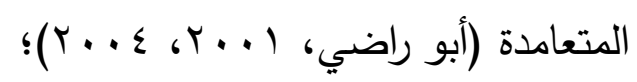

تجنب الأخطاء الثائعة في الرسمبيانات بطرح الأسئلة المناسبة حول البيانات وتقييم مدى استجابتها لها؛ اختيار الرسوم حسب أفضلية الخطاطات

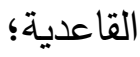

فكثيرا ما نجد أحياء متجاورة في السجل المصفوفي وكذلك متجاورة جغرافيا. لذلك وقع التعبير عنه بشريحتين من الألوان المتدرجة في منحيين لتقريب مفهوم الاتصال والانفصال للقارئ.

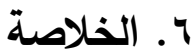
تم بحثنا التقييمي والتقويمي حول الرسوم البيانية في الأطالس من خلال مقاربة علامية-سيميولوجية شاملة تستهدف أساسا إفادة المستخدم. كان الغرض ملارله من ذلك تطبيقُ هذه المقاربة في الأطالس الجغرافية كما هو الثأن بأطلس جدة الرقمي. وقع استعراض التهاه أهم المحطات للمسار التاريخي لنثأة الرسوم البيانية وقلة الأدبيات النظرية لها. ركزنا على المقاربة العلامية-السيميولوجية التي نظرَّر لها بيرتين واستتبط حزمة من القواعد العامة والخطاطات الأساسية للرسوم البيانية أو الرسمبيانات. أكدنا على الفائدة الحاصلة من خلال اعتماد مثل هذه المبادئ والخطاطات وقمنا بتقييم بعض الأمثلة عن الرسوم البيانية وكيف يمكن تحسينها وفق المقاربة العلامية-السيميولوجية التي لتي لتئية تركز على القراءة الإجمالية. والقراءة الإجمالية تكرس المقاربة الكليانية التي تهتم بالكل قبل الجزئيات والتفاصيل التي لا تجيب إلا عن الأسئلة الجزئية،

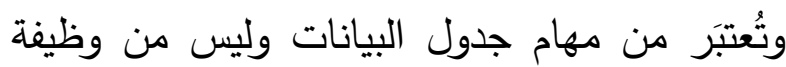

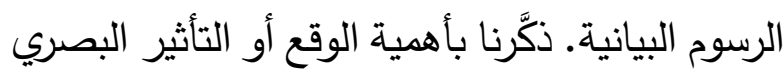
للرسم البياني الذي ينبغي أن يقوم على البناء المتعامد

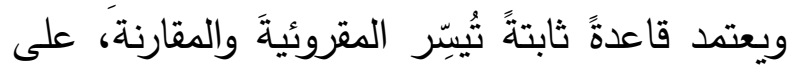
عكس البناءات الدائرية. ثم حاولنا أخيرا إثباتَ تصنَّ 
والمادي لهذا المشروع بالمنحة البحثية رقم - (G75)

$$
\text { .1436-125-479) }
$$

الباحث الرئيس

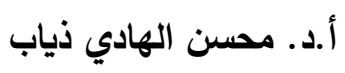

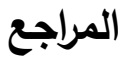

\section{المراجع العربية: - أمبية}

ا ـ أبو راضي، فتحي عبد العزيز ، خرائط التوزيعات

البشرية ورسومها البيانية، دار النهضة العربية،

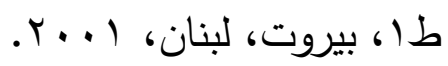

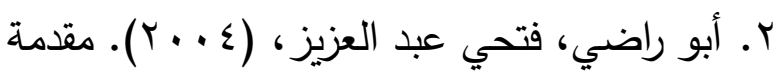

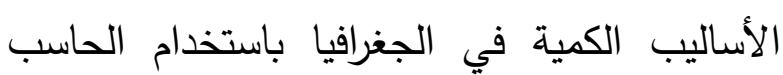
الآلي، دار المعرفة الجامعية، الإسكندرية، مصر .

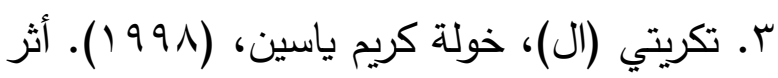
تدريس قواعد اللغة العربية باستخدام الرسوم البيانية في التحصيل واستيفاء المعلومات وتجنب الخطأ النحوي، أطروحة دكتوراه (غير منشورة)، جامعة

$$
\text { بغداد، كلية التربية، 1991 19. }
$$

ع. خريشة، علي، وغازي خليفة، (997 (19) فعالية استخدام الجداول والرسوم البيانية في فهم طلاب وعلئ الصف السادس في الأردن للمعلومات الجغرافية، مجلة أبحاث اليرموك، سلسلة العلوم الإنسانية، المجلد الثالث عشر ، العدد الثاني.

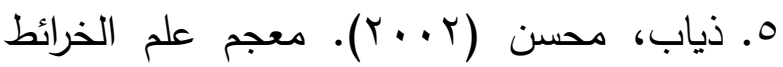
والعلوم المجاورة عربي - إنكليزي - فرنسي مع مدخل عربي ومدخل إنكليزي، مركز النشر الجامعي تونس

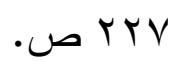

وجوب احترام قواعد الترتيب والتصنيف والتبسيط في الرؤيا حسب المقروئية الحاصلة؛ اللجوء إلى اعتماد القيم النسبية إلى جانب القيم

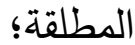
تنكيك الرسوم المركبة لتبسيط قراءة الصور

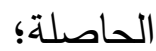

إيلاء الأهمية في التعامل مع القيم الاستثنائية

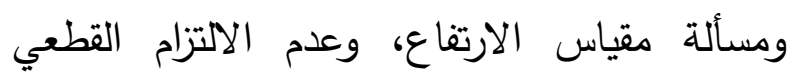

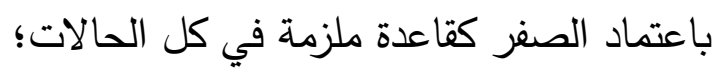
احترام المقاييس الأفقية والعمودية في كل الرسوم

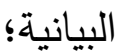

• تجنب تحميل الرسوم المعقدة على الخرائط بل الاكتفاء بالبيانات التأليفية المصنفة؛ التصميم الجيد للرسمبيانات بتوفير عناصر باتهر

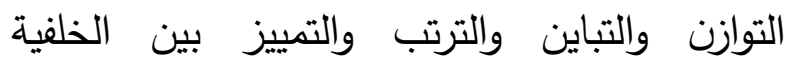
والأمامية. وهي نقاط لابد من تطويرها في بحث ولتبن

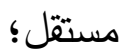
توسيع مجال استخدام الرسوم البيانية في علوم ومواد أخرى كالمجالات التقليدية كالجغرافيا وعلم الإحصاء أو في (التكريتي، 991 ( ) أو في المسائل

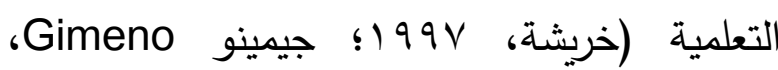

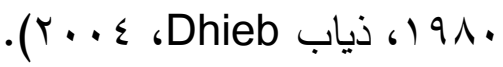

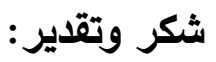
يتقدم فريق الدراسة بالثكر لعمادة البحث العلمي،

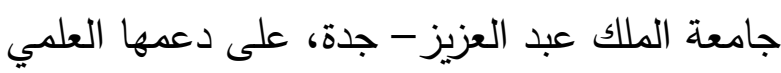




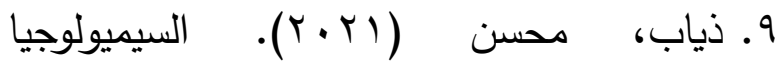

الرسمبيانية- الرسمبيانات-الثبكات الرسمبيانية-

الخرائط، مركز النشر الجامعي بجامعة الملك عبد

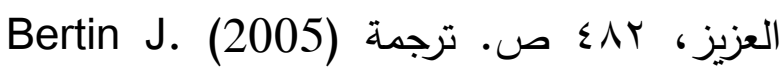

Sémiologie Graphique. Les كتاب diagrammes-Les réseaux-Les cartes.

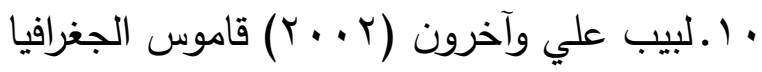
عربي-فرنسي-إنجليزي. منشورات شمال-جنوب 2002تونس344 ـ مساهمة بجزء مصطلحات علم الخرائط. ا ا.مسدي (ال) عبد السلام (•99 (1)). الأسلوبية والأسلوب. الدار العربية للكتاب، الطبعة الثالثة، الثبل الثبله

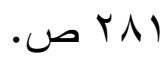

r ا.وزارة التعليم العالي (9 (1 اهـ). أطلس المملكة

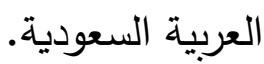

\section{المراجع الفرنسية}

13. AMADO (1994). Analyse graphique d'une matrice de données. Ed. Saint-Mandé: CISIA.

14. Bertin J. (1967). Sémiologie graphique. Les diagrammes, les réseaux et les cartes. Paris, éditions Mouton, Gauthier-Villars.

15. Bertin, J., (197v). Sémiologie graphique. Les diagrammes-Les réseaux-Les cartes. Second Ed. Paris: Gauthier-Villars, première édition, $431 \mathrm{p}$.

16. Bertin, J., (1970). La graphique. Communications, $\quad$ N. 15, numéro thématique : L'analyse des images, 169 185.

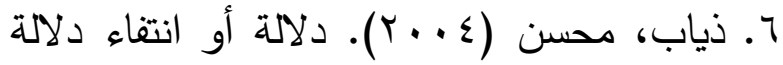

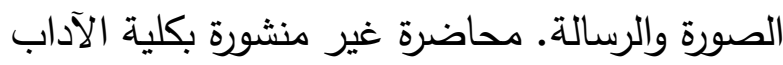
والعلوم الإنسانية بصفاقس، وحدة البحث تحليل

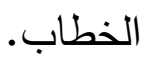

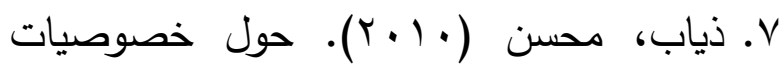
القراءة الخرائطية؟ الندوة العلمية حول القراءة وإشكالية المنهج - - - عمان. ^. ذياب، محسن (ع ا • Y). مظهر الخرائط. دراسة

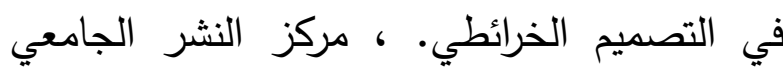

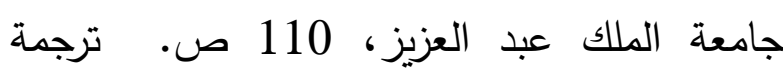
Robinson, A. H. (1952). The Look of Maps. An Examination of Cartographic Design. Esri Press.

17. Bertin, J., (1973). Sémiologie graphique. Les diagrammes-Les réseaux-Les cartes. Second Ed. Paris: Gauthier-Villars.

18. Bertin, J., (197`). Graphique et traitement graphique de l'information. Flammarion.

19. Bertin, J., (2005). Sémiologie graphique. Les diagrammes-Les réseaux-Les cartes. (4th Ed., reviewed and augmented.) Paris: EHESS.

20. Bonin, S. (1983). Initiation à la graphique. Ed. Épi, Paris. 
21. Bord Jean-Paul et Blin Eric (1995). Initiation géo-graphique, ou comment visualiser son information (Français) Broché Editeur : CDU SEDES; Édition : 2e éd. remaniée augmentée (18 décembre 1995)

22. Brinton W.C. (1919). Graphic Methods for Presenting Facts. Ed The engineering Magazine company, New York.

23. Dhieb M., (1989). Le traitement d'une série de données multivariées par une méthode graphique le fichier-matrice. Revue "Géographie et Développement " $N$ 8-9, 1989.

24. Dhieb M., (1992). Approche multivariée et typologie de l'espace Tunisien, la technique de la collection de cartes. Les Cahiers du CERES "série Géographie $N^{\circ} 7$.

25. Dhieb M., (1993a). Les traitements graphiques multivariés méthodes d'évaluation et perspectives d'évolution. Les Cahiers du CERES، série géographie, $N$. 8); $\quad$ http://www;ceres;rnrt;tn/revuetunisienne-des-sciences-sociales.

26. Dhieb M., (1993b). Problématique de la représentation des données quantitatives multivariées un point de vue graphique, Revue Tunisienne des Sciences Sociales $N^{\circ} 113$, pp; 9-38, CERES, Tunis;

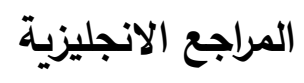

34. Balchin, W.G., (1976). Graphicacy. American Cartographer, 3 (1). Retrieved from https://doi.org/10.1559/152304076784 080221.

35. Bertin, J., (1987). Semiology of Graphics: Diagrams, Networks, Maps. (Translated by W. Berg) Madison, WI: University of Wisconsin Press.

36. Dhieb M., (2019). Translating Bertin into Arabic today: new hidden facets of Semiology of Graphics, published in http://www;ceres;rnrt;tn/revue-tunisiennedes-sciences-sociales.

27. Dhieb M., (1993c). Une nouvelle méthode graphique: la matrice géographique, Poster, Congrès UGI, Glasgow.

28. Dhieb M., (2017). Traduire encore Bertin aujourd'hui pourquoi faire? Les nouvelles faces cachées de la Sémiologie Graphique. Proceedings online, ICC Washington, 2-7 July. http://adsabs.harvard.edu/abs/2018PrICA... 1...27D

29. Dhieb Mohsen et al. ( $(\cdot 19)$. De l'intérêt des cartes: Approche sémiologique des cartes issues des SIG., Colloque International de Marrakech (in progress).

30. Dhieb, M. (1981). Le traitement graphique des séries statistiques : L'exemple de la population mondiale. $\mathrm{PhD}$, University of Paris I, Panthéon - Sorbonne.

31. Gimeno, R., (1980). Apprendre à l'Ecole par la Graphique, Paris : Retz.

32. Gronoff, J.-D., (1983). EURISTA : Logiciel d'aide d'interprétation des données en Sciences Humaines. In Informatique et Sciences Humaines; N. 58, Paris, Mouton.

33. Muller, J.C., (1984). Sériation visuelle et sériation automatique. International Yearbook of Cartography, XXIV, pp.131148.

Cartography and Geographic Information Science, Volume $46 \underline{\text { Issue }}$ 2.

37. Dhieb, Mohsen, Mohammed Al-Amri, Abdelhameed Jamil (2019). The Digital Urban Atlas of Jeddah: Some Raised Issues and Semiological Principles. Current Urban Studies, Vol.7 No.2(2019), Paper ID 93490, 23 pages. DOI: $\underline{10.4236 / \text { cus.2019.72013 }}$

38. Dhieb M., (2013a). Geographic Information Systems and Graphic Visualization; preliminary note. Les Cahiers du CERES, Série Cartographie 
N.3 "L'information Géographique et le monde changeant". Texts collected and reviewed by M. Dhieb, pp. 21-31. ISBN: 978-9973-902-59-7.

39. Dhieb Mohsen (2013c). Semiological aspects of urban maps: A case study from the Holy city of Mecca, published online

https://icaci.org/files/documents/ICC_pr oceedings/ICC2013/_extendedAbstract/8 5_proceeding.pdf

40. Dhieb M., (2017). The Atlas of Jeddah and the implementation of new principles of graphic semiology; "ICC 2017, Washington 2-7 July;

41. Friendly Michael (2008). A Brief History II.1 of Data Visualization.

42. George K. Zipf (1949). Human Behavior and the Principle of Least Effort. Addison-Wesley. "Online text [1]" https://archive.org/details/in.ernet.dli.2 $\underline{015.90211}$

43. Monmonier M. S. (1985). Technological transition in cartography. Madison, Wis.: University of Wisconsin Press, 1985. ISBN 0-299-10070-7.

44. Muehrcke P.C. (1986). Map Use : Reading, Analysis, Interpretation. J.P. Publications, Madison, $512 \mathrm{p}$.
45. Playfair William (1807). An Inquiry into the Permanent Causes of the Decline and Fall of Powerful and Wealthy Nations [archive], p. 102.

46. Robinson, A. H., (2015). The Look of Maps. Translation from English into Arabic of the book by Dhieb, M., Edition of Scientific Publication Centre, King Abdulaziz University, ISBN 9960-06772-6.

47. Tufte, Edward R. (2001). The Visual Display of Quantitative Information, Cheshire, CT, Graphics Press, 2001， $2^{\text {nd }}$ ed. $\left(1^{\text {st }}\right.$ ed. 1983), 197 p. (ISBN 978-0-9613921-4-7)

48. Tufte, Edward R. (1990). Envisioning Information, Cheshire, CT, Graphics Press, 1990, $11^{\mathrm{e}}$ éd. (ISBN 978-09613921-1-6, LCCN 90166920)

49. Tufte, Edward R. (1997). Visual Explanations : Images and Quantities, Evidence and Narrative, Cheshire, CT, Graphics Press, 1997, $2^{d}$ ed. (ISBN $978-$ 0-9613921-2-3, LCCN 97127584)

50. Zipf George Kingsley (1949), Human behavior and the principle of least effort, Addison-Wesley Press. 


\title{
A semiological approach to complex graphics treatment in Geographical Atlases. Application of the orderable matrix technique on Jeddah city.

\author{
Pr. Dr. Mohsen DHIEB , Dr. Mohammed Al-Amri , Dr. Abdelhamed Jamil
}

Department of geography and GIS, Faculty of Arts and Humanities,

\section{King Abdulaziz University.}

\begin{abstract}
. the modern digital revolution has had a profound impact on cartographic and graphic techniques and outputs, especially on atlases. The modern "Technological Transition" has taken various forms and contributed to the development of digital atlases, because of cartographic automation and intense use of "CAD 8 ", "GIS", and "GISc"10".

However, the Atlas graphics are still suffering, from the authors' point of view, from a serious deficiency in semiology, and observing various pitfalls from the user's perspective. Many graphics are chosen randomly from dedicated software, and some types of graphics are used intensively instead of others, more appropriate. Thus, superposed columns, pie charts or spiral diagrams, are frequent in geographic research, despite their poorness and proven disadvantages. Some lacks depart from design errors, since graphics are presented as means of beautification or decoration and nor as means of communicating messages, from the perspective of their effectiveness and the extent to which they fulfill their basic function of communication. Therefore, we believe that the creators of data, geographers first and other specialists of humanities second, should choose appropriate graphic types and achieve good design, from a scientific-psychological perspective. This is to facilitate to users the process of reading and understanding graphics, according to the theory of the readability of the graphic image as a rational image before being an artistic one. The reason is that most graphic products pay more attention to the issues of collecting, analyzing, and presenting data outputs by using (CAD), (GIS) and (GISc), than assimilating and providing useful messages to the widest users' category, especially when it comes to multiple and long data series.
\end{abstract}

After presenting the theoretical background of graphic design with regards to the theories of image and communication, the research objectives of this paper are: to review the history and recent evolution of graphic communication; to witness the need of carefulness and objectiveness in choosing appropriate data for the atlases; to find alternative solutions for good design of tedious graphics, based on Berlin's schemes; to facilitate the process of visual perception of symbols; to understand the real graphic messages conveyed by graphics; and to avoid the most important errors in creating and designing graphic data. The implementation of these objectives is based on a review on Bertin's heritage semiological techniques and to implement one of these techniques, i.e. the matrix file in the Jeddah Digital Atlas Project.

\footnotetext{
${ }^{8}$ Computer-Aided-Design

${ }^{9}$ Geographic Information Systems

${ }^{10} \mathrm{GISc}$ refers to Geographic Information Sciences.
} 